\title{
Linking GCM-simulated climatic changes to ecosystem models: case studies of statistical downscaling in the Alps
}

\author{
Dimitrios Gyalistras ${ }^{1}$, Hans von Storch ${ }^{2}$, Andreas Fischlin ${ }^{1}$, Martin Beniston ${ }^{3}$ \\ ${ }^{1}$ Systems Ecology, Swiss Federal Institute of Technology Zurich (ETHZ), Institute of Terrestrial Ecology, Grabenstrasse 3 , \\ CH-8952 Schlieren, Switzerland \\ ${ }^{2}$ Max-Planck-Institut für Meteorologie, Bundesstrasse 55, D-20146 Hamburg, Germany \\ ${ }^{3}$ Institute of Geography, Swiss Federal Institute of Technology Zurich (ETHZ), Winterthurerstrasse 190, CH-8057 Zurich, \\ Switzerland
}

\begin{abstract}
Based on the statistical approach proposed by von Storch et al. (1993; J. Clim. 6: 1161-1171), a general, flexible method to assess changes in the local climatic inputs of ecosystem models from largescale climatic changes as simulated by general circulation models (GCMs) was developed, verified and applied at 5 Swiss locations for the summer and winter seasons. According to the requirements of various ecosystem models, at each location 17 seasonal statistics related to daily temperatures, precipitation, sunshine duration, air humidity and wind speed were considered. Year-to-year variations of the local variables were linked by means of Canonical Correlation Analysis to simultaneous anomalies in the North Atlantic/European sea-level pressure and near-surface temperature fields. The analysis was performed for the period 1901 to 1940, separately for each season and location. In all cases, physically plausible statistical models were found which quantified the local effects of changes in major circulation patterns, such as the strength of westerly flow in winter and of large-scale subsidence in summer. In the verification interval 1941 to 1980 , most variables were better reconstructed in winter than in summer, and better at the 3 north alpine than at the 2 south alpine locations. The best-reconstructed variables were seasonal mean daily temperatures and daily temperature extremes, for which on average 42 to $75 \%$ of the total variances over the verification interval at the different locations could be explained. Explained variances for precipitation totals were 29 to $55 \%$ in winter and 10 to $28 \%$ in summer, and for mean daily relative sunshine durations in both seasons ca 12 to $53 \%$. Seasonal mean relative humidities, mean wind speeds, and within-summer standard deviations of daily variables were generally poorly reproduced. It was found that the procedure of von Storch et al. can be generally improved by using, in addition to sea-level pressure, the near-surface temperature as a large-scale predictor. Improvement was strongest for temperaturerelated variables, and for the summer season. The established statistical relationships were applied to anomaly fields as simulated by the Hamburg fully coupled atmospheric/oceanic ECHAM1/LSG GCM under increasing atmospheric greenhouse gas concentrations. The procedure yields time-dependent, internally consistent, and regionally strongly differentiated climatic change estimates for several important ecosystem inputs, at a spatial resolution far above the resolution of present GCMs.
\end{abstract}

KEY WORDS: Regional climate scenario - GCM - Statistical downscaling - Ecosystem model - Impact study $\cdot$ Mountains

\section{INTRODUCTION}

In order to study possible impacts of climatic change on particular ecosystems, models of these systems are of major importance. Although ecosystems and the atmosphere interact on a multitude of temporal and spatial scales, most impact studies consider only the 'oneway' forcing of the ecosystems by the atmosphere.
Yet, in ecosystem studies a large variety of climatic input requirements occurs. For example, in order to drive ecosystem models (Parry et al. 1988, Spitters et al. 1989, Roth et al. in press) or insect population models (Lischke \& Blago 1990), specific combinations of several meteorological variables such as temperature, precipitation, photosynthetically active radiation, wind, or air humidity, with an hourly to daily time step, and 
for at least the duration of the vegetation season, are needed. On the other hand, forest gap models (Shugart 1984) simulating forest succession require realisations of mean temperatures and precipitation totals for every month of the year (Fischlin et al. 1995), and Schröder's (1976) population dynamics model for red deer requires monthly snow heights.

To study and assess the impacts of climatic change, a given set of such inputs needs to be derived from appropriate climatic change scenarios. A scenario at a particular location and moment should be internally consistent at least with respect to changes in those climatic parameters which are needed either as direct model inputs (Fischlin 1982, Brzeziecki et al. 1993) or to stochastically generate the weather variables that drive the ecosystem model (e.g. Mearns et al. 1984, Supit 1986, Swartzman \& Kaluzny 1987, Wilks 1992, Fischlin et al. 1995).

Climatic change scenarios should extend from the present to an appropriate point in the future, or otherwise cover time spans that are long enough for the purposes considered. In some cases, e.g. agroecosystems, a few decades can be sufficient. When, however, soils or forests are considered, which respond to climate on time scales of several centuries (Bugmann \& Fischlin $1992,1994)$, the scenarios should specify the transient behavior of regional climates for at least a few hundred years.

Further, the climatic inputs are typically needed at specific representative locations, i.e. with a spatial resolution of a few kilometres or less. A high spatial resolution is of particular importance if ecosystems are studied within a complex topography such as the Alps.

Three basic approaches could be adopted to derive the needed regional climatic change scenarios (Giorgi \& Mearns 1991): (1) Construct regional climatic change analogues from past climatic situations as inferred from proxy data (Flohn \& Fantechi 1984, Wigley et al. 1986) or instrumental records (e.g. Wigley et al. 1980, Pittock \& Salinger 1982, Lough et al, 1984, Hulme et al. 1990). (2) Use numerical models, such as general circulation models (GCMs) or limited area meteorological models (LAMs; e.g. Giorgi et al. 1990) embedded in GCMs, to simulate possible future climatic conditions with the best possible spatial detail. (3) Use, as an intermediate solution, semiempirical approaches establishing a statistical relationship between largerscale and regional climatic changes (e.g Kim et al. 1984, Wilks 1989) which then can be applied to derive climatic change scenarios from the outputs of spatially coarse numerical models (Karl et al. 1990, Wigley et al. 1990, von Storch et al. 1993).

A major advantage of the first, purely empirical, approach is that it is relatively simple to implement. However, paleoclimatic analogues normally provide information only on few parameters, such as mean temperatures and, less often, precipitation (Wigley et al. 1986). In addition, the temporal resolution of proxy data is often coarse, and, even if yearly data are available (e.g. from tree rings), the annual cycle may not be well resolved (Stockton et al. 1985, Schweingruber 1988). Though this is not the case for instrumental records, there still remains the problem that past climatic changes do not necessarily reflect the effects of increasing greenhouse gas concentrations on climate (Giorgi \& Mearns 1991). Also, due to the lack of deterministic models it is difficult to formulate gradual shifts in future climates in a physically consistent manner.

The second approach relies upon GCMs. Since GCMs reproduce most large-scale atmospheric and oceanic features, present - and even more so future - climate models are regarded as being capable of reliably simulating at least the broad large-scale aspects of man-made climatic change (Dickinson 1986. Gates et al. 1990). Simulations of time-dependent changes for the next $100 \mathrm{yr}$ or so are becoming increasingly available (Manabe et al. 1991, 1992, Cubasch et al. 1992, Gates et al. 1992), thereby providing vast amounts of physically consistent data with a time step of $1 \mathrm{~h}$ or less.

However, a problem occurs due to the coarse horizontal resolution of most currently used climate models, which is in the order of $500 \mathrm{~km}$, and which sharply contrasts with the fine resolution required by ecosystem models. Furthermore, the minimum spatial scale at which GCMs produce acceptable results lies above several gridpoint intervals. For present GCMs this is at least 2000 to $4000 \mathrm{~km}$ (von Storch et al. 1993). Climatic changes obtained at individual gridpoints seem even less reliable over mountainous areas such as the Alps, which are not well represented in GCMs. This is illustrated in Fig. 1 which compares the performance of the ECHAM1/LSG GCM (described below in 'Data and methods - GCM experiments') at 3 gridpoints in the vicinity of the Alps with measurements from the 5 case study locations considered in this study. Though in the GCM 'control' experiment (simulation of present climate) the observed annual cycle of temperature is reproduced qualitatively correctly, with a flat maximum in July/August and a minimum in January (not shown), the GCM generally overestimates the amplitude of the annual cycle by several degrees. In particular, note that the model error is similar in magnitude to the average changes simulated by the GCM at the 3 alpine gridpoints under the 'IPCC Scenario A' for future atmospheric greenhouse gas concentrations (Fig. 1a). Precipitation is severely underestimated at all locations during the summer months. Here the projected changes in gridpoint precipitation under the 'IPCC Scenario A' are much 
Fig. 1 Comparison of the climate simulated by the ECHAM1/LSG GCM in the vicinity of the Alps (averages from 3 gridpoints) to observations. (a) Monthly mean temperatures. Thick line: differences between the means simulated in the years 2075-2084 of the GCM 'IPCC Scenario A' experiment and the means from the 'control' experiment. Thin lines: deviations of observations from the 'control' The following annual mean temperatures were subtracted prior to calculation of the deviations: Bever, $1.5^{\circ} \mathrm{C}$; Bern, $8.4^{\circ} \mathrm{C}$; Davos, $3.0^{\circ} \mathrm{C}$; Lugano, $11.7^{\circ} \mathrm{C}$; Saentis, $-2.1^{\circ} \mathrm{C}$; 'control', $8.7^{\circ} \mathrm{C}$. (b) Monthly precipitation totals. Thick lines: simulated annual cycles. Thin lines: observed annual cycles

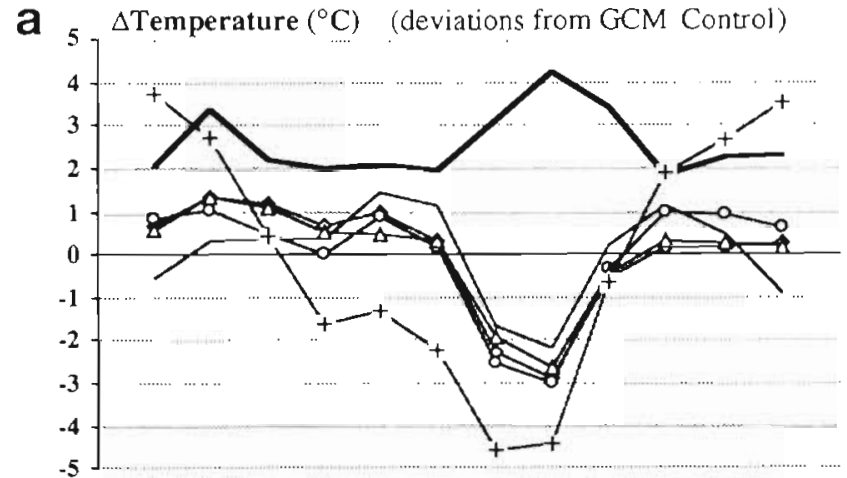

\section{b 28 Precipitation ( $\mathrm{cm} / \mathrm{month})$}

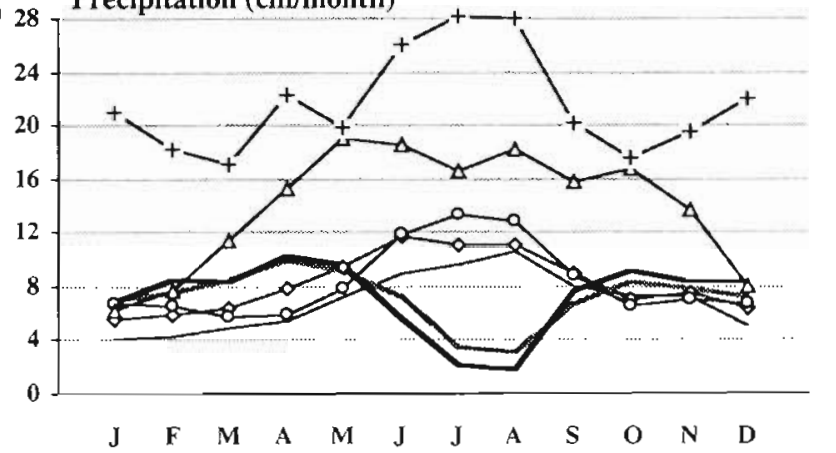

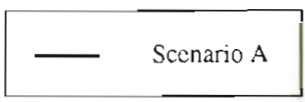
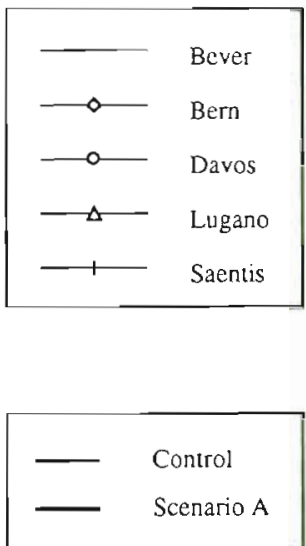

smaller than the deviations typically found between the observations and the 'control' (Fig. 1b).

One possibility for improving the simulation of regional climates is to increase the horizontal resolution of the GCMs, or at least to use them to drive simulation models with enhanced resolution over areas of interest (LAMs). However, computational costs of climate models increase at least quadratically with the spatial resolution (Giorgi \& Mearns 1991). It may therefore be expected that, even if more powerful computers become available, the simulation of the full annual cycle over several decades, let alone centuries, by high-resolution models will not be possible for several years to come. Furthermore, even if gridpoint distances for long-term integrations could be reduced to $100 \mathrm{~km}$ or less, there would still remain a substantial gap between the scales at which climate models would be reliable and the local detail required by most ecosystem models.

An alternative is to use semiempirical approaches which allow site-specific empirical data to be combined with the physically consistent results of numerical climate models. Semiempirical approaches are particularly attractive since, in principle, they can be flexibly used at any location and for any variable of interest. Moreover, due to their computational efficiency they would even allow transient scenarios far into the future to be derived.

To date, several semiempirical approaches have been proposed. For example, Wigley et al. (1990) used monthly means of several regionally averaged atmospheric variables to predict monthly mean surface temperature and precipitation perturbations at the 32 climate stations within the region considered; Karl et al. (1990) related daily gridpoint data of 22 freeatmosphere variables to daily temperature extremes, precipitation and cloud ceilings from local surface observations; von Storch et al. (1993) used anomalies of large-scale mean sea-level pressure over the Atlantic to predict, using Canonical Correlation Analysis (Barnett \& Preisendorfer 1987), changes in winter mean Iberian precipitation; finally, Werner \& von Storch (1993) used basically the same approach to relate January-February mean temperatures from 11 Central European stations to large-scale circulation.

The method of von Storch et al. (1993) appears to be superior, because, unlike the other approaches, it considers the large-scale (several $10^{3} \mathrm{~km}$ ) behavior of a climatic parameter, according to the assumption that predictions of future climates by GCMs are most credible within this resolution. Also, unlike the approach by Karl et al. (1990), the statistical models obtained do not depend on a particular GCM and can thus be flexibly applied to several GCMs. However, the method of von Storch et al. (1993) has so far been applied only to predict 1 climate variable at a time, i.e. rainfall or temperature, and only for winter.

Thus the following questions arise: Is it possible by means of this method to establish plausible statistical 
relationships which allow multivariate descriptions of local climates, even in a complex orography like the Alps, to be linked to large-scale climatic changes? If yes, for which ecosystem inputs, seasons and locations can the best results and for which the poorest results be obtained? What improvements could be gained by modifying the method, for instance by including large-scale near-surface temperature anomalies as an additional predictor? Finally, is it possible to derive regionally differentiated scenarios from GCM-projected global climatic changes?

In this paper the method of von Storch et al. (1993) was used for the first time to downscale large-scale climatic changes - at a seasonal resolution, not only for winter but also for summer - to 17 local ecosystem inputs at several point locations within a complex topography, i.e. at 5 representative case study locations in the Alps. We show that the method proposed by von Storch et al. (1993) not only yields physically plausible results for all case study locations, but that it can also be substantially improved, in particular for temperature-related variables. Finally, by applying the obtained statistical relationships to 2 climatic change experiments with a GCM, we demonstrate that our approach allows the derivation of regionally differentiated, transient climatic change scenarios of use in ecosystem studies.

\section{DATA AND METHODS}

\section{Observations}

As independent variables (predictors) we tested mean sea-level pressure (SLP) and $2 \mathrm{~m}$ above-ground air temperature, for which long-term (several decades) observed data sets are available. The independent variables were given on a $5^{\circ} \times 5^{\circ}$ latitude by longitude grid containing 153 gridpoints and extending from $40^{\circ} \mathrm{W}$ to $40^{\circ} \mathrm{E}$ and $30^{\circ} \mathrm{N}$ to $70^{\circ} \mathrm{N}$ (Fig. 2a).

Winter (Dec, Jan, Feb) and summer (Jun, Jul, Aug) mean SLP for the years 1901 to 1980 were calculated at each gridpoint from daily values provided in the NCAR data set (Jessel 1991). Seasonal mean near-surface ( $2 \mathrm{~m}$ above-ground) temperatures were derived for the same period from monthly data given on a $10^{\circ} \times 5^{\circ}$ latitude by longitude grid (Vinnikov et al. 1987, Jessel 1991), and were then interpolated to the $5^{\circ} \times 5^{\circ}$ standard grid. Missing data for some years and gridpoints were replaced by interpolation between adjacent timepoints.

The SLP data were initially given as absolute values, whereas the near-surface temperature data were given as anomalies from the 3 different base periods 1881-1935, 1881-1940 and 1881-1960. However, since fitting of the statistical models required data with zero means, anomalies were calculated for both predictors relative to the mean states of the respective years used (see also 'Statistical procedure', below).

On the regional scale, 5 different locations within Switzerland, representative of north, central and south alpine climates, were considered (Fig. 2b): (1) Bern [valley, $565 \mathrm{~m}$ above sea level (m.a.s.l.); $7.4^{\circ} \mathrm{E}, 46.9^{\circ} \mathrm{N}$ ] at the northern slope of the Alps; (2) Davos (pronounced valley location, 1590 m.a.s.l.; $9.8^{\circ} \mathrm{E}, 46.8^{\circ} \mathrm{N}$ ) in the central alpine region; (3) Bever (1712 m.a.s.l.; $9.9^{\circ} \mathrm{E}, 46.6^{\circ} \mathrm{N}$ ), located in the Oberengadine valley, which is characterized by a central or south alpine climate; (4) Lugano (valley, 273 m.a.s.l.; $9^{\circ} \mathrm{E}, 46^{\circ} \mathrm{N}$ ) at the southern slope of the Alps; and (5) Saentis (mountain peak, 2500 m.a.s.1.; $9.4^{\circ} \mathrm{E}, 47.3^{\circ} \mathrm{N}$ ) which represents 'free-atmosphere' conditions at the northern side of the Alps. a

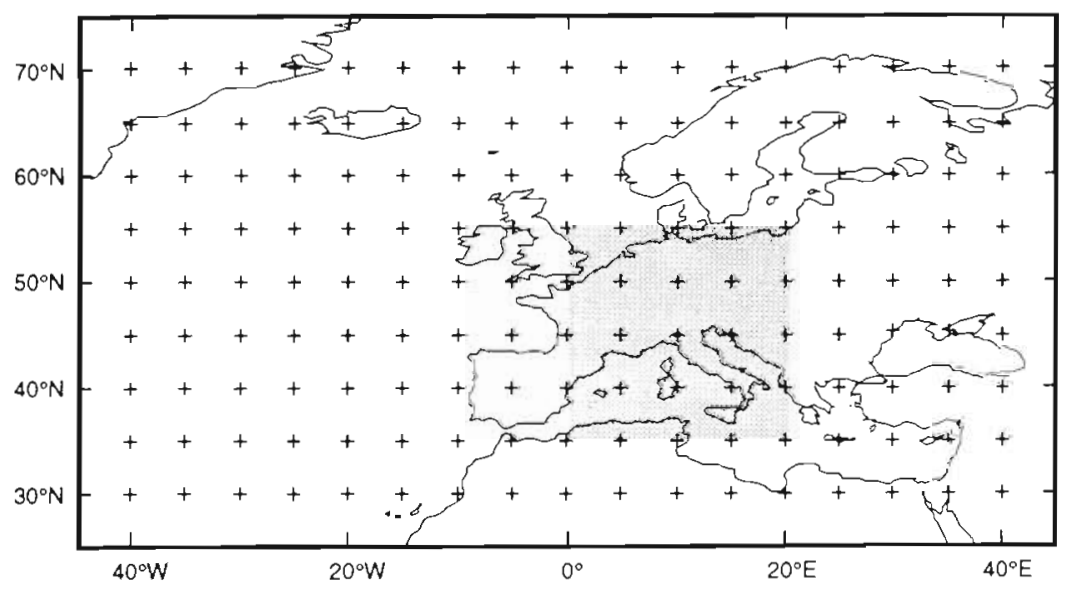

b

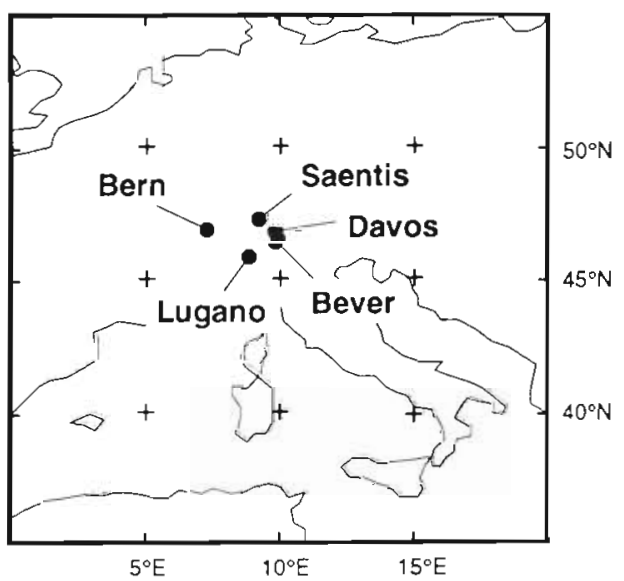

Fig. 2. (a) Gridpoints of sea-level pressure and near-surface temperature fjelds used in this study. (b) The 5 Swiss locations considered 
Table 1. Meteorological variables and the related seasonal statistics considered in this study

\begin{tabular}{|c|c|c|}
\hline Variable & Seasonal statistics & Explanations \\
\hline Temperature & $\begin{array}{l}\text { (a) } T_{\text {mean }}, T_{\min }, T_{\max }, T_{\text {ampl }} \\
\text { (b) } s\left(T_{\operatorname{mean}}\right), s\left(T_{\min }\right) \\
\\
s\left(T_{\max }\right), s\left(T_{\text {ampi }}\right)\end{array}$ & $\begin{array}{l}\text { (a) Mean }\left({ }^{\circ} \mathrm{C}\right) \\
\text { (b) Standard deviations of daily mean, minimum and maximum tem- } \\
\text { peratures and of daily temperature amplitude, respectively }\left(\text { in }{ }^{\circ} \mathrm{C}\right)\end{array}$ \\
\hline Precipitation & $\begin{array}{l}\text { (a) Precip. } \\
\text { (b) } s \text { (Precip.) } \\
\text { (c) } N \text { days } \geq 1 \mathrm{~mm}\end{array}$ & $\begin{array}{l}\left.\text { (a) Mean ( } \mathrm{cm}^{-1}\right) \\
\text { (b) Standard deviation of daily precipitation (in } \mathrm{cm}) \\
\text { (c) Number of days with fotal } \geq 1 \mathrm{~mm}\end{array}$ \\
\hline $\begin{array}{l}\text { Relative sunshine } \\
\text { duration }\end{array}$ & $\begin{array}{l}\text { (a) Rel. sunsh. } \\
\text { (b) s(Rel. sunsh.) }\end{array}$ & $\begin{array}{l}\text { (a) Mean (\%) } \\
\text { (b) Standard deviation of daily average from } 3 \text { measurements per day (in } \% \text { ) }\end{array}$ \\
\hline Relative humidity & $\begin{array}{l}\text { (a) Rel. hum. } \\
\text { (b) s(Rel. hum.) }\end{array}$ & $\begin{array}{l}\text { (a) Mean (\%) } \\
\text { (b) Standard deviation of daily average from } 3 \text { measurements per day (in \%) }\end{array}$ \\
\hline Wind speed & $\begin{array}{l}\text { (a) Wind } \\
\text { (b) s(Wind) }\end{array}$ & $\begin{array}{l}\text { (a) Mean ( } \mathrm{m} \mathrm{s}^{-1} \text { ) } \\
\text { (b) Standard deviation of daily average from } 3 \text { measurements per day (in \%) }\end{array}$ \\
\hline
\end{tabular}

The dependent variables (predictands) were given at each location as vectors of 17 seasonal weather statistics (Table 1). Special emphasis was given to the main weather elements temperature and precipitation, for which 11 variables were defined. Relative sunshine duration was included as a variable, allowing us to approximate incoming photosynthetically active radiation, which determines rates of plant growth in many ecosystem models. As additional parameters we considered relative air humidity and wind speed, which are used particularly in agroecosystem models. Withinseason standard deviations of all meteorological variables were included, since these parameters are typically needed to simulate daily weather conditions by means of stochastic weather generators. Since precipitation distributions often show considerable skewness, we used, as an additional parameter for the withinseason variability of rainfall, the number of days with precipitation $\geq 1 \mathrm{~mm}$, which is proportional to the probability of 'wet days' within the season. The threshold value of $1 \mathrm{~mm}$ was chosen because it represents the lower limit for the detection of rainfall by most measuring devices (cf. Uttinger 1970).

All seasonal statistics were derived from daily 1901 to 1980 measurements, extracted from the database of the Swiss Meteorological Institute (SMA), Zurich (SMA 1901-1980, Bantle 1989). Daily mean temperatures, relative sunshine durations, relative humidities and wind speeds were calculated from 3 measurements per day, whereas daily temperature minima and maxima were determined as the extremes among the 3 daily measurements and the evening temperature of the previous day. After 1971 the time at which the evening temperature measurements were taken was changed from 21:30 h to ca 19:00 h, so daily means for the years 1901 to 1970 and 1971 to 80 were calculated according to different procedures (Bantle 1989). The effects of this change in procedure are still being investigated by the SMA; for locations with large daily temperature amplitudes it is likely that, due to the new procedure, daily mean temperatures are overestimated by ca $0.2^{\circ} \mathrm{C}$ (A. de Montmollin, SMA, pers. comm.).

\section{GCM experiments}

Simulated seasonal mean SLP and near-surface temperature were obtained from experiments performed with a fully coupled global atmospheric/oceanic GCM run at the Max Planck Institute for Meteorology (MPI), Hamburg, Germany. The atmosphere component (ECHAM1) of the model is a version of the spectral numerical forecasting model of the European Centre for Medium Range Weather Forecasts, extensively modified at the MPI Hamburg for climate simulations. Its horizontal resolution is limited by a cut-off at wave number 21, corresponding to a gaussian grid with an average spacing of $5.6^{\circ}$, and its vertical resolution is given by 19 levels in a hybrid $\sigma$-p coordinate system. The ECHAM1 model simulates the diurnal cycle with a time step of $40 \mathrm{~min}$. The ocean component (LSG), which allows for the calculation of large-scale geostrophic motions, is based on 11 variably spaced vertical levels, an effective horizontal grid-size of $4^{\circ}$ and a basic time step of $30 \mathrm{~d}$, except for the 2 uppermost ocean layers, where a time step of $1 \mathrm{~d}$ is used. A more detailed description of the coupled model is given in Cubasch et al. (1992).

All GCM-simulated data used in this study were derived from daily GCM outputs and were interpolated on the $5^{\circ} \times 5^{\circ}$ grid of the observed data sets. We considered results from (1) the 'control' integration with constant 1985 atmospheric $\mathrm{CO}_{2}$ concentration, (2) the 'double $\mathrm{CO}_{2}$ ' ( $\left.\mathrm{DCO}_{2}\right)$ experiment, representing 
the model system's response to an immediate doubling of greenhouse gas concentrations from 360 to $720 \mathrm{ppm}$ equivalent $\mathrm{CO}_{2}$, and (3) the 'IPCC Scenario A' (SCNA) experment, where the GCM is forced by time-dependent greenhouse gas concentrations according to the 'Business-As-Usual' scenario given by Houghton et al. (1990) The model's performance in the 'control' run and its responses to the greenhouse gas forcings are addressed later.

\section{Statistical procedure}

Our method is based upon a 'Perfect Prog' approach (Glahn 1985, von Storch et al. 1993). A statistical relatronship is first established between the large-scale and the local observations, and then applied unmodified to predict changes in the local variables from any large-scale observations or GCM-simulated data sets. For this purpose, we considered each season and location separately.

The overall procedure consists of (1) the selection of 2 subperiods, one to fit and one to verify the statistical models, (2) the calculation of anomalies, plus the weighting of the predictor and predictand variables, (3) the estimation of a series of differently specified statistical models linking the predictands to the predictors, (4) the verification of all specified models with independent observations, (5) the selection of a subset of the best-performing models, and finally (6) the application of the selected models to GCM anomaly fields (Fig. 3)

In the standard procedure we used the years 1901 to 1940 for model estimation and the years 1941 to 1980 for model venfication. In order to test the sensitivity of the resulting climatic change scenarios to the choice of estimation period, the 2 subperiods were reversed at a later stage.

All varlables were transformed to deviations from the mean states of the years used for model estimation. This is because only anomalies of the large-scale and local variables were related to each other, whereas the longterm means were not affected by the procedure. On the local side, this ensures that climatic change scenarios can be specicied in a manner consistent with present long-term mean clımate at each location, whereas on the side of the large-scale predictors only the differences occurring between a climatic change experiment and the 'control' experiment of a GCM need to be con-

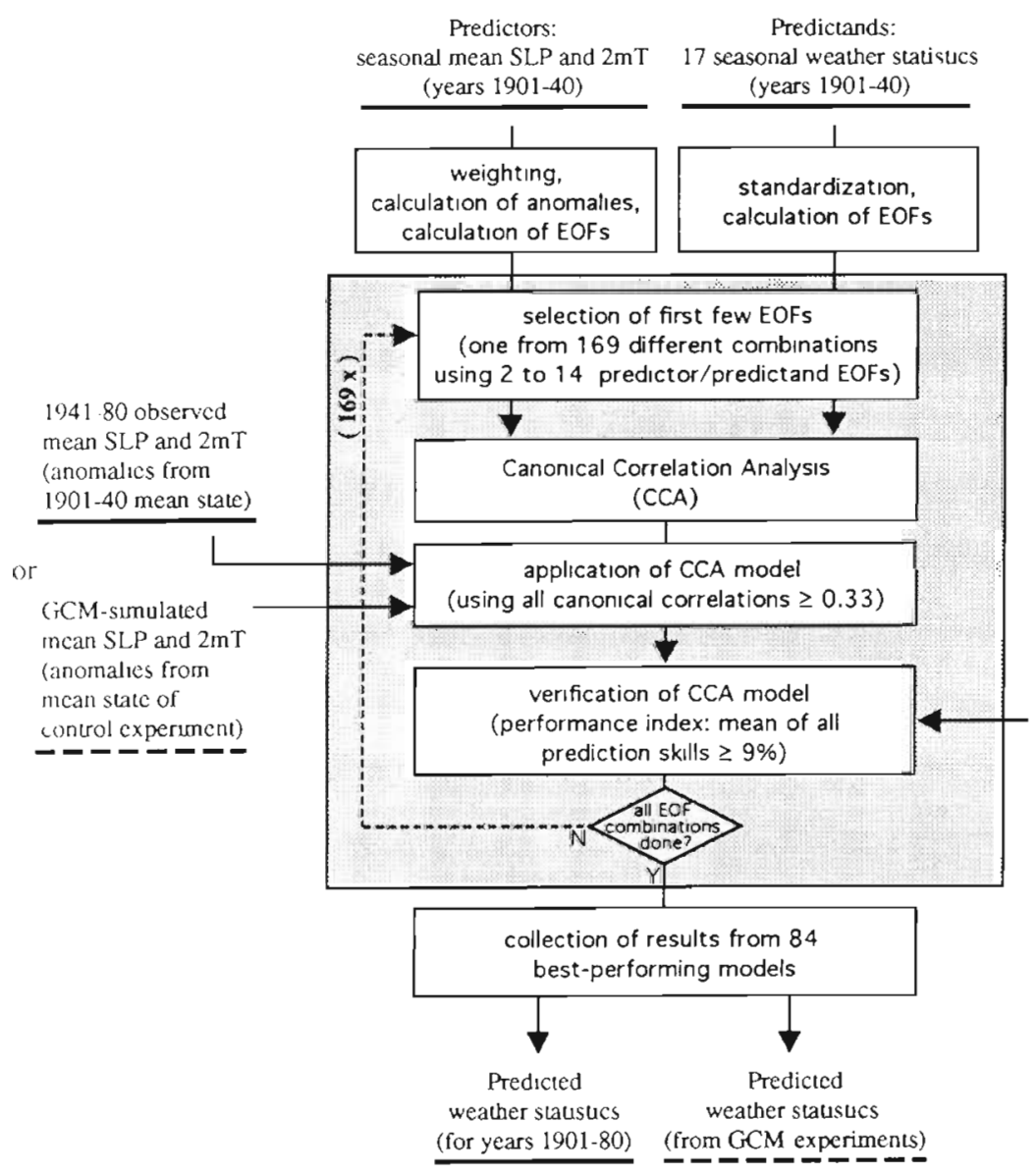

1941-80 observed weather statistics

Fig 3 Block diagram of the method used to derive local climatic change scenarios from large-scale climatic changes as simulated by GCMs Underlined text = input/output data sets, boxes = procedures; solid lines with arrows $=$ flow of data; dashed line with arrow $=$ Jteration over procedures within grey box. $2 \mathrm{mT} 2 \mathrm{~m}$ above-ground temperature. For further explanations see text 
sidered. The use of anomaly fields avoids the problem. that the long-term mean fields simulated by GCMs are normally biased with respect to observations.

The predictor variables were weighted with the square root of their latitude cosine, in order to account for the latitudinal variation of the box sizes of the rectangular $5^{\circ} \times 5^{\circ}$ grid. When both SLP and nearsurface temperature were used as predictors, each field was rescaled with a constant factor in order to account for a predefined proportion (e.g. half) of the total predictor variance. For graphical representations of predictor patterns, however, all weightings were removed, such that the same unit applied to all variables of the same kind. The local weather statistics were weighted with their observed standard deviations from the years used for model estimation, thus eliminating the effects of different value ranges.

Estimation of the statistical models consisted of 2 steps: first dimensionality of the observed data sets was reduced and linear dependencies between variables within the same data set were removed by estimating separately for the $n_{x}$ predictors $x_{j}\left(j=1, \ldots, n_{x}\right)$ and for the $n_{y}$ predictands $y_{k}\left(k=1, \ldots, n_{y}\right)$ the eigenvectors of the respective 2 nd-moment matrices, i.e. the empirical orthogonal functions (EOFs; e.g. Kutzbach 1967, Ehrendorfer 1987). Then, the time coefficients (i.e. the estimated principal components or PCs) of the first $N_{x}$ predictor and the first $N_{y}$ predictand EOFs were related to each other by means of Canonical Correlation Analysis (CCA; e.g. Anderson 1984, Barnett \& Preisendorfer 1987). Based on the eigenvectors of the squared covariance matrix of the PCs, CCA identifies $n_{c}=\operatorname{Min}\left(N_{x}, N_{y}\right)$ linear combinations of the predictor $\mathrm{PCs}$ which correlate best with respective linear combinations of the predictand PCs. The scalars determining these linear combinations were transformed from the EOF space back to the physical space, yielding $n_{c}$ canonical patterns $P_{i}$ and $Q_{i}\left(i=1, \ldots, n_{\mathrm{C}}\right)$ for the predictors and predictands, respectively. Each pair of patterns corresponds to a canonical mode. The canonical patterns were used to infer from the $x_{j}$ and $y_{k}$ 2 new sets of variables, the canonical time coefficients $s_{i}$ and $t_{i}\left(i=1, \ldots, n_{c}\right)$, according to the equations

$$
\begin{aligned}
& S_{i(t)}=\sum_{j=1}^{n_{x}} P_{i j}^{\prime} X_{j(t)} \\
& t_{i(t)}=\sum_{k=1}^{n_{y}} Q_{i k}^{\prime} Y_{k(t)}
\end{aligned}
$$

respectively. (Primes denote transposition of a matrix.) The $P_{i}$ and $Q_{i}$ are determined by CCA under the constraint that all $s_{i}$ as well as all $t_{i}$ are mutually uncorrelated, but that the first pair of time coefficients $\left(s_{1}, t_{1}\right)$ shows a maximum canonical correlation $\rho_{1}$. Every further pair $\left(s_{m}, t_{m}\right)$ of time coefficients, correlating with a factor $\rho_{m}\left(m=2, \ldots, n_{c}\right)$, can be used to explain a maximum of the remaining variance of the respective data sets.

When using both SLP and near-surface temperature as predictors, the $x_{j}$ may be subdivided into SLP anomalies $(j=1, \ldots, 153)$ and near-surface temperature anomalies $(j=154, \ldots, 306)$. Accordingly, an individual pattern $P_{i}$ was visualised as being composed of 2 separate maps defined by the corresponding elements $P_{i j}$. The associated time coefficient $s_{i}$ may be given as the sum of 2 signals:

$$
S_{i(\ell)}=\sum_{j=1}^{153} P_{i j}^{\prime} X_{j(1)}+\sum_{j=154}^{306} P_{i j}^{\prime} X_{j(1)}
$$

Due to the respective orthogonality of the $s_{1}$ and $t_{j}$ the element $P_{i j}$ (or $Q_{i k}$ ) of the $i$ th canonical pattern represents the covariance between the $j$ th predictor (the $k$ th predictand) and the dimensionless coefficient $s_{j}\left(t_{i}\right)$. Local maxima (minima) in the predictor maps of the $i$ th canonical mode thus represent regions where positive (negative) anomalies in the respective $x_{\text {, contribute }}$ with large positive anomalies to the coefficient $s_{i}$ (cf. Eq. 1 or $1^{\prime}$ ). Similarly, a large positive (negative) value of $Q_{t k}$ denotes that for the $i$ th canonical mode a large positive (negative) anomaly of the $k$ th weather statistic occurs, if the time coefficient $t_{i}$ takes a positive value. Finally, the canonical correlation $\rho_{i}$ between $s_{i}$ and $t_{i}$ measures the strength with which anomalies in the predictands and predictors are related to each other within the respective canonical mode.

The results of CCA can be used to predict linearly, from any anomaly fields describing changes in the predictors $x_{j}$, the simultaneous responses of all local weather statistics $y_{k}\left(k=1, \ldots, n_{y}\right)$, according to

$$
y^{*}{ }_{k(t)}=\sum_{i=1}^{n_{\mathrm{CU}}} t^{*}{ }_{i(t)} Q_{i k}=\sum_{i=1}^{n_{\mathrm{CU}}} \rho_{1} \frac{\sigma_{s_{j}}}{\sigma_{t_{i}}} s_{i(l)} Q_{i k}
$$

Here, $n_{\mathrm{cu}} \leq n_{\mathrm{c}}$ is the number of canonical modes used, $t^{*}{ }_{i(t)}$ denotes the estimated $i$ th time coefficient of the dependent variables, and $\sigma_{s_{j}}$ and $\sigma_{t_{i}}$ are the standard deviations of the time coefficients $s_{i(t)}$ and $t_{i(t)}$, respectively. For each CCA model fitted, we chose $n_{c u}$ individually as the number of all canonical correlations $\rho_{i}$ above the threshold value $\eta_{c}=0.33$. For the choice of $\eta_{c}$ we assumed that serial correlation in the predictors and predictands can be neglected due to the interannual variations considered. Given that CCA systematically overestimates the true $\rho_{j}$, a value of $\eta_{c}$ was hereby chosen that was larger than the critical value of 0.26 (or 0.31 ) above which an unbiased estimate of a correlation coefficient would be significantly different from zero at the $90 \%$ (or 95\%) confidence level (2sided $t$-test, $n=40$; e.g. Kreyszig 1977).

Performance of CCA may sensitively depend on the numbers $N_{x}$ and $N_{y}$ of EOFs considered. Using too 
many EOFs will fit the statistical models too strongly to the particular data sets considered, most likely missing an adequate description of the underlying stochastic process. Too few EOFs, on the other hand, will omit part of the significant signal, thus resulting in a poorer predictive ability of the overall model. In the present study, instead of retaining a significant, fixed number of EOFs based on EOF-selection rules (e.g. Preisendorfer et al. 1981), we focused on the effects resulting from possible alternative choices for $N_{x}$ and $N_{y}$. For this purpose we performed CCA for the $13^{2}=169$ combinations resulting when varying $N_{x}$ and $N_{y}$ individually within the range of 2 to 14 . The upper limit of 14 EOFs was chosen because, from this number on, typically more than $90 \%$ of the total variances of the predictor and predictand data sets could be accounted for, for all seasons and locations considered.

Each of the $169 \mathrm{CCA}$ models was then applied to predict the local variables from the large-scale data not used for model estimation, and model performance was assessed according to

$$
\psi_{\left(e_{x}, e_{y}\right)}=\frac{1}{n_{y}} \sum_{k=1}^{n_{y}} \operatorname{Max}\left(0, \operatorname{Cor}\left(y_{k(t),} y_{k(t)}\right)-\eta_{v}\right)
$$

$\psi$ measures the mean of all correlations above the threshold value $\eta_{v}=0.3$ between the observed $\left(y_{k}\right)$ and reconstructed $\left(y^{*}\right)$ weather statistics in the 40 yr verification period. The value chosen for $\eta_{v}$ can be justified similarly as was done for $\eta_{\mathrm{c}}$ above.

The 84 (half of 169) best-performing models were then used to evaluate the performance of the procedure for the individual weather statistics, and to derive climatic change scenarios from the GCM experiments.

\section{RESULTS AND DISCUSSION}

\section{Model estimation}

We investigated 5 different variants of predictor data sets, with the SLP and near-surface temperature fields accounting for the total variance of all predictors as given by the ratios $1: 0$ (i.e. only SLP), $2: 1,1: 1,1: 2$ and $0: 1$ (only temperature). For the predictor data sets of SLP alone, SLP and near-surface temperature with equal weight, and temperature alone, the canonical patterns and time coefficients of individual CCA models were graphically represented and visually compared with each other and between locations.

In this subsection we mainly present results using Bern as an example, since results obtained for Bever, Davos, Lugano and Saentis could be interpreted similarly to those for Bern. We also present only CCA models fitted to a combined predictor data set (SLP and near-surface temperature with equal weight), because the canonical patterns resulting when using only 1 field were found to be quite similar to the respective subpatterns of the combined approach. This was generally the case for both seasons considered.

\section{Winter}

Fig. 4 shows the CCA model obtained for $N_{x}=N_{y}=4$ for Bern in winter. The first predictor pattern consists of a large positive SLP anomaly centred over the United Kingdom, a negative temperature anomaly over land areas, and a positive temperature anomaly over the Atlantic with an increasing amplitude towards the northwest. The 2 subpatterns give a consistent picture: in winters with on average higher than normal pressure over the UK, mean westerly flow and thus advection of relatively mild maritime air towards the continent are less pronounced, such that temperatures over land areas drop below their long-term means. At the same time, advection of polar air into the northwest Atlantic is also reduced, resulting in above-normal temperatures in this region. This was the dominant predictor pattern in winter for all locations considered.

The first canonical pattern of the weather statistics in Bern (Fig. 4c, solid bars) confirms the above interpretation: temperatures are anomalously low, as are precipitation, its standard deviation, and the number of days where precipitation exceeds $1 \mathrm{~mm}$. The negative responses in the precipitation-related variables are plausible, indicating that advection of maritime air is the main source of winter precipitation in Bern. Since the sign of the canonical patterns is arbitrarily determined by CCA, note that the following interpretation also holds: a negative SLP anomaly centred over the UK, indicating intensified mean westerly flow, is associated with anomalously high temperatures over the continent, and also implies positive temperature and precipitation anomalies in Bern.

The relevance of the large-scale patterns for the individual weather statistics can be seen from Fig. $4 \mathrm{~d}$. Shown are the proportions of the variances in the local variables which were explained by the time coefficients $t_{1(\ell)}$ (solid bars) and $t_{2(\ell)}$ (shaded bars), i.e. the squared correlation coefficients (in percent) between the $y_{*}$ : and $t_{i(t)}$ for the model estimation period 1901 to 1940

The second canonical mode mainly explained the variability of winter mean daily temperature extremes and amplitudes, mean relative sunshine duration, and its within-season standard deviation (Fig. 4d, shaded bars). Positive anomalies in those variables (Fig. 4c shaded bars correlate with anomalously high SLP over southern Europe (Fig. 4b, left), which implies intensified mean advection of warm air from the west/southwest, and thus elevated temperatures over the conti- 
nent with a maximum over eastern Europe (Fig. 4b, right). The responses of the weather statistics are consistent, since predominance of high pressure over central/southern Europe also means for Bern more frequent occurrence of cloudless winter days, with more sunshine, but also with larger radiative energy loss during the nights, resulting in higher daily temperature amplitudes.

The third and fourth canonical modes (not shown) also contributed to explaning the year-to-year vari- ability of the weather statistics. The third predictand pattern represented predominance of meridional flow from the north/northeast, which at Bern was associated with below-normal temperatures and mean wind speed, with higher-than-normal within-season temperature variability and increased relative humidity. The fourth predictand pattern showed a large positive SLP anomaly over the mid-latitude Atlantic and corresponding large-scale positive near-surface temperature anomalies over Finland; it correlated mainly with

a
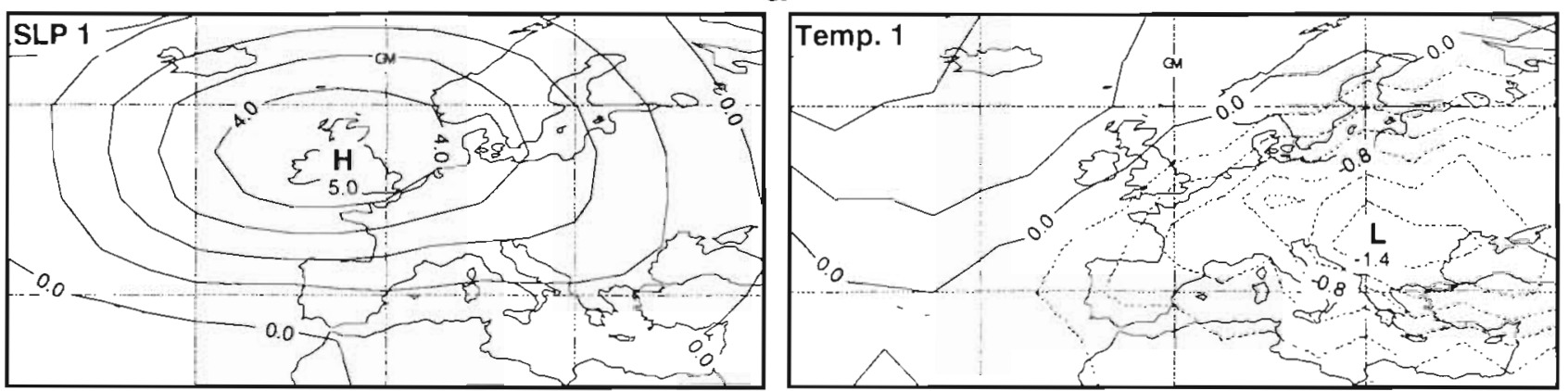

b
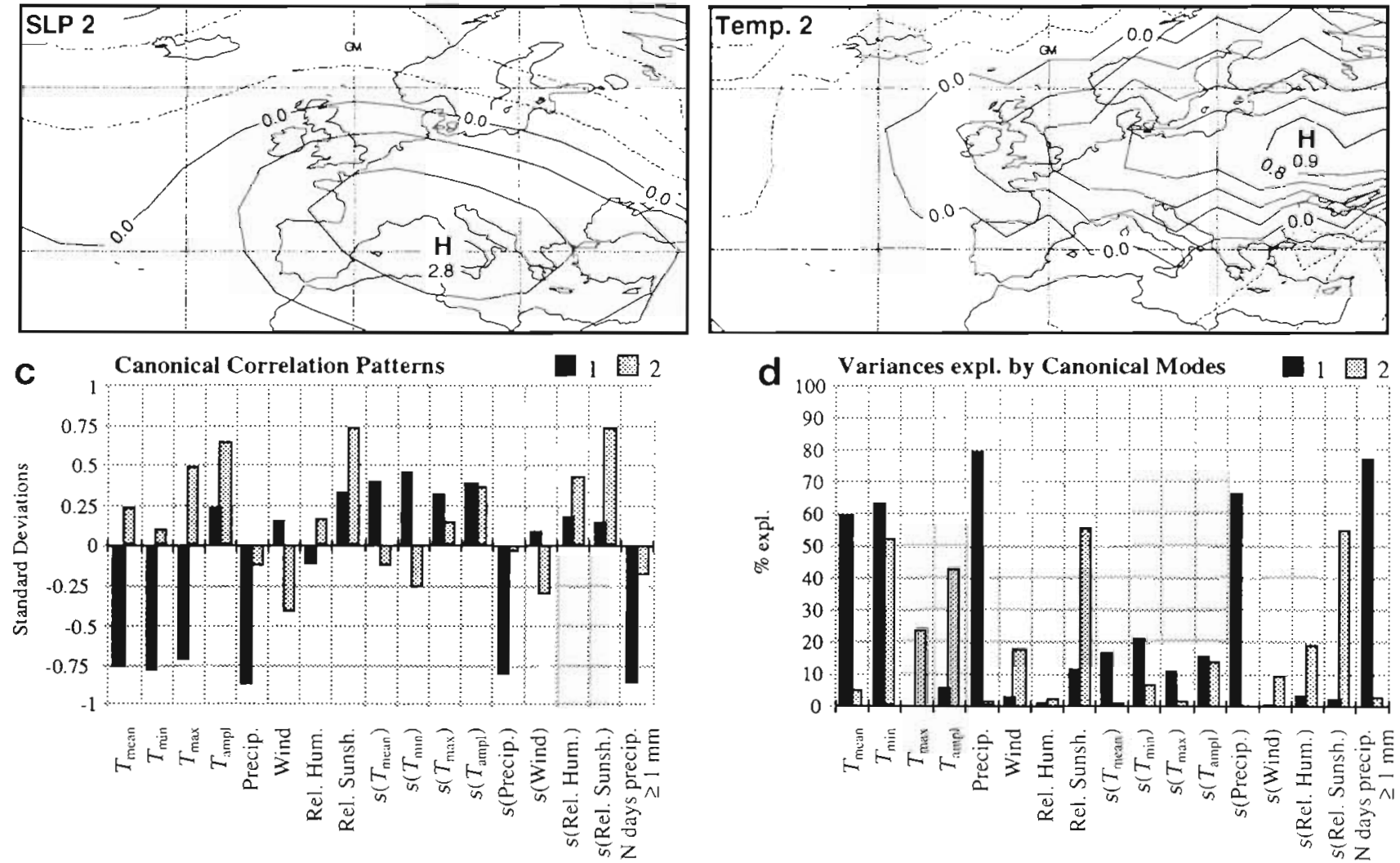

Fig. 4. CCA model for Bern in winter. (a) First and (b) second canonical patterns for the predictors. Left sides of (a) and (b): SLP subpatterns, contour interval $1 \mathrm{mb}$. Right sides: near-surface temperature subpatterns, contour interval $0.2^{\circ} \mathrm{C}$. (C) Canonical patterns, (d) explained variances for the local weather statistics. The first 4 predictor EOFs and the first 4 weather statistic EOFs were used, explaining ca 75 and $77 \%$ of the respective total variances. Correlations between time coefficients are 0.89 for the first and 0.82 for the second mode 
negative deviations in the within-season standard deviations of daily temperature means and extremes The third and the fourth mode showed canonical correlations of 0.55 and 0.37 , respectively, such that they also contributed to the reconstruction of the weather statistics in the model verification phase.

The canonical correlation patterns obtained for Davos (Fig. 5) illustrate the regionally differentiated relationships established by means of CCA. For example, in contrast to Bern, year-to-year variations of winter mean precipitation, its within-season standard deviation, and the probability of precipitation events $\geq 1 \mathrm{~mm}$ (Fig. 5d, shaded bars) were explained in Davos mainly by the second canonical mode (cf. Fig. 5b), not by the mean strength of westerly flow. In addition, though the respective SLP and temperature subpatterns were qualitatively similar for Bern and Davos, regional differentiation was also given by shifts in the locations and/or amplitudes of the pattern's troughs and ridges. Due to sampling uncertainties, however, it

a
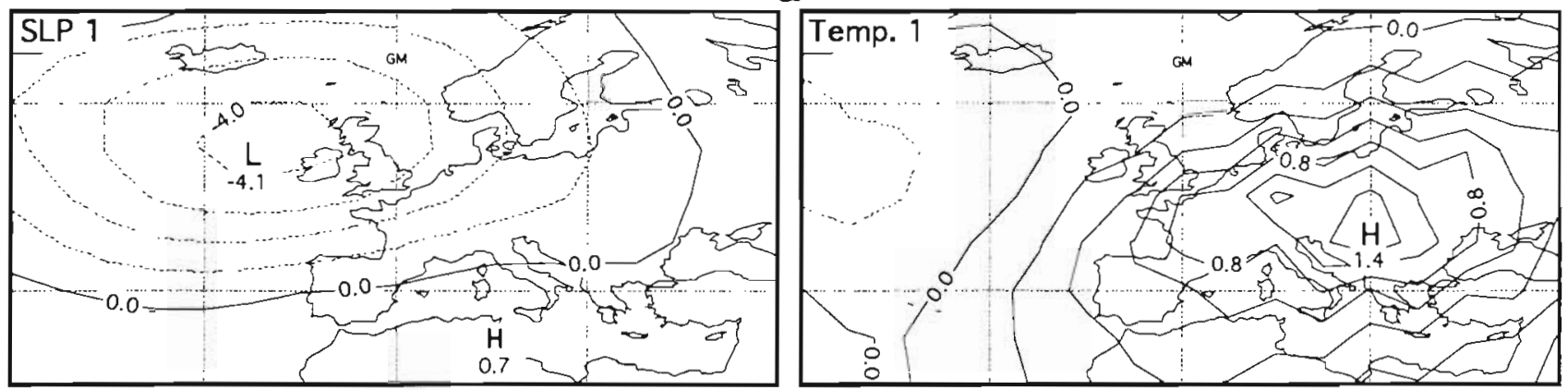

b
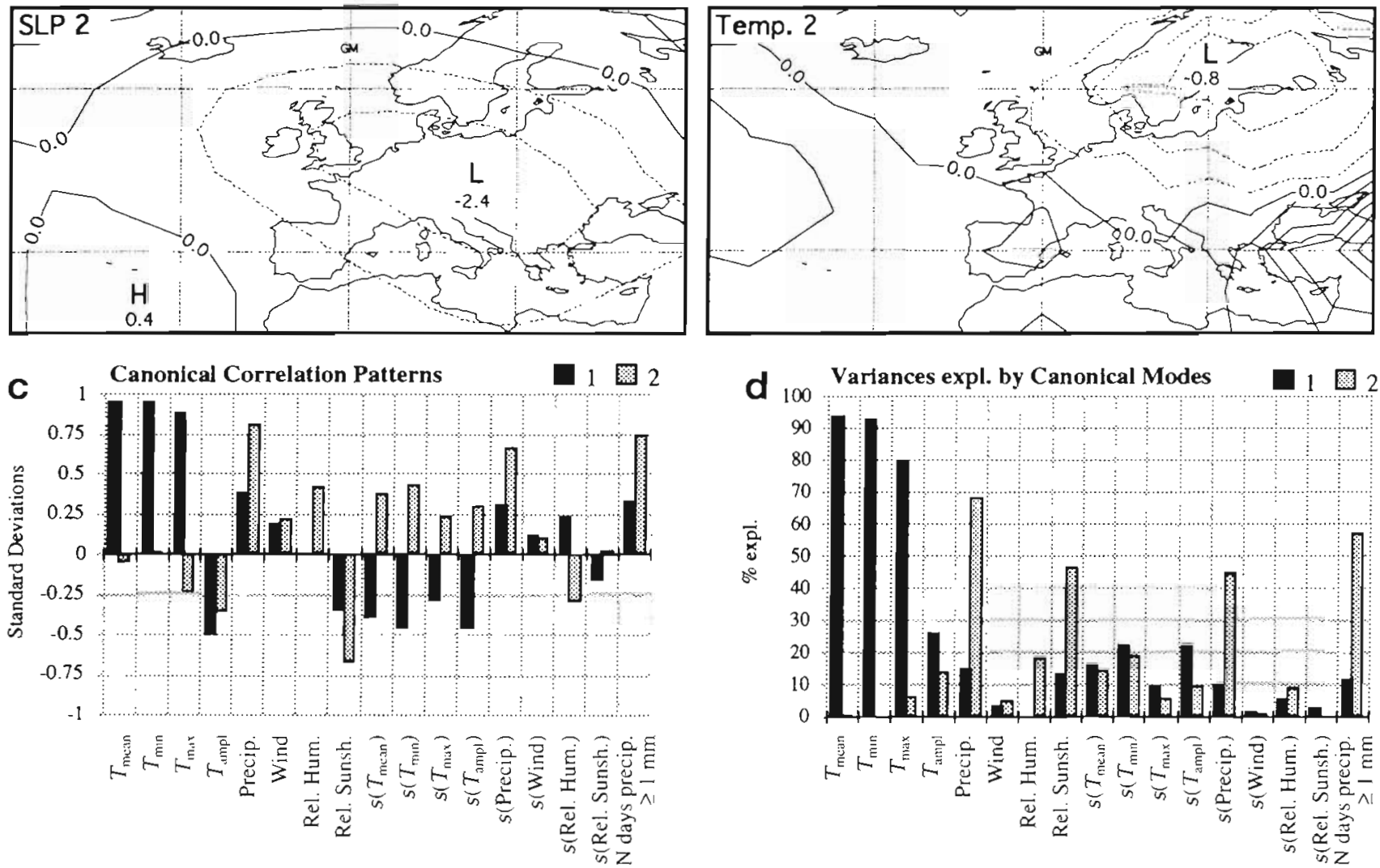

Fig. 5. CCA model for Davos in winter. (a) First and (b) second canonical patterns for the predictors. Left sides of (a) and (b): SLP subpatterns, contour interval $1 \mathrm{mb}$. Right sides: near-surface temperature subpatterns, contour interval $0.2^{\circ} \mathrm{C}$. (c) Canonical patterns, (d) explained variances for the local weather statistics. The first 7 predictor EOFs and the first 4 weather statistic EOFs were used, explaining ca 88 and $73 \%$ of the respective total variances. Correlations between time coefficients are 0.91 for the first and 
a
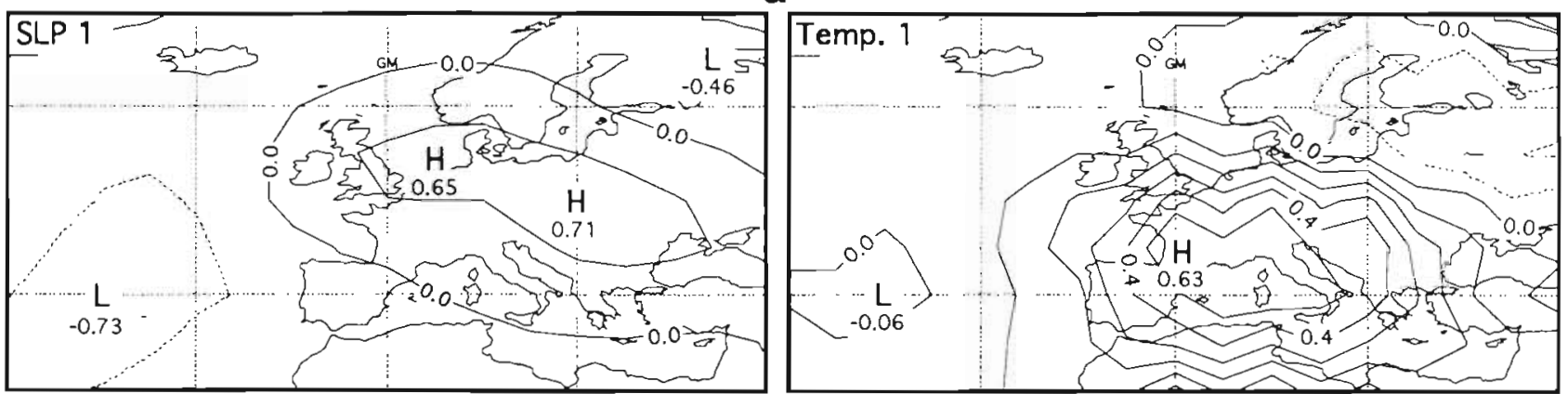

b
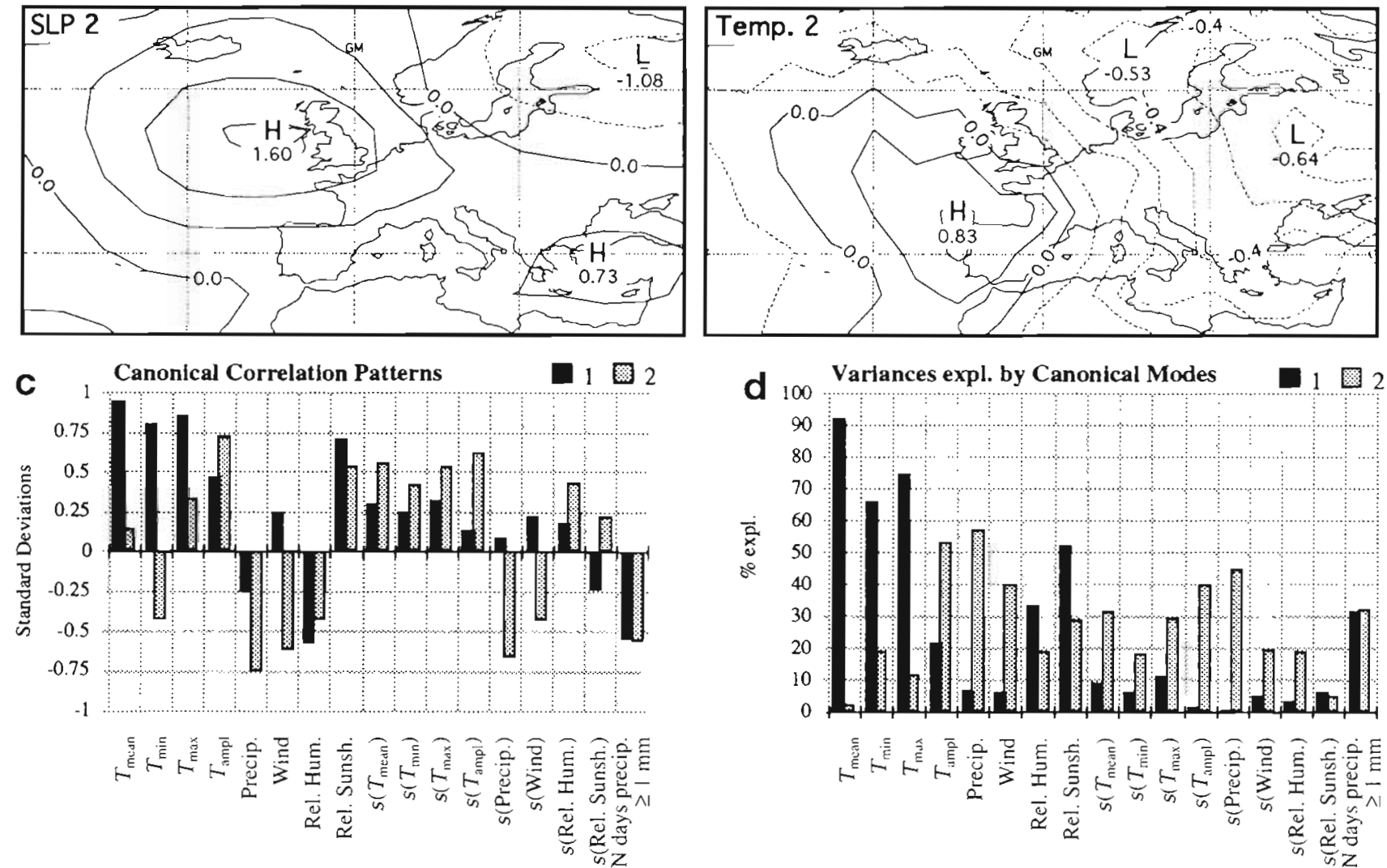

Fig. 6. CCA model for Bern in summer. (a) First and (b) second canonical patterns for the predictors. Left sides of (a) and (b): SLP subpatterns, contour interval $0.5 \mathrm{mb}$. Right sides: near-surface temperature subpatterns, contour interval: $0.1^{\circ} \mathrm{C}$. (c) Canonical patterns, (d) explained variances for the local weather statistics. The first 4 predictor EOFs and the first 4 weather statistic EOFs were used, explaining ca 75 and $77 \%$ of the respective total variances. Correlations between time coefficients are 0.89 for the first and 0.75 for the second mode

could be that not all respective patterns are significantly different from each other.

\section{Summer}

Fig. 6 shows the results of CCA with $N_{x}=4$ and $N_{y}=$ 3 for Bern in summer. Again, the first predictor pattern depicted here for Bern was typical for all other locations as well. Its SLP subpattern (Fig. 6a, left) shows a small positive anomaly over Europe (ca $0.7 \mathrm{mb}$ ) when compared to the 1901-1980 standard deviation of mean summer SLP, which ranges from ca $0.8 \mathrm{mb}$ over the Mediterranean area to ca $2 \mathrm{mb}$ over the UK and Scandinavia (not shown). Considering that in the longterm mean the fringe of the Azores high-pressure system reaches eastern Europe (not shown), the pattern can be interpreted to reflect summers with less pronounced subsidence over the Azores, but with the Azores high extending further than normal into the 
continent, thus leading to predominantly stable, warm weather conditions over central Europe. An alternative explanation could also be, however, that the SLP subpattern represents a weak circulation induced by anomalously high temperatures over central and southern Europe.

Consistent with both interpretations, the first canonical mode predicts for Bern positive temperature and relative sunshine duration anomalies and a smaller probability for precipitation events $\geq 1 \mathrm{~mm}$ (Fig. 6c, solid bars). Interpreted with opposite signs, the first canonical mode describes summers with a higherthan-normal SLP over the Azores, but a corresponding low SLP over Europe, denoting that the continent is more frequently exposed to intrusions of cold air from the west/northwest. This results in anomalously low temperatures at Bern, as well as over large areas southeast of the anomalously low SLP.

The second mode described mainly changes in the precipitation-related variables (cf. Fig. 6d, shaded bars): similar to the situation in winter, higher-thannormal SLP centred over the UK (Fig. 6b, left) denotes summers with generally weaker westerlies and reduced advection of maritime air into central Europe, whereas the associated intensified northwesterly flow implies negative near-surface temperature anomalies over eastern Europe (Fig. 6b, right). In Bern, precipitation-related variables show negative deviations; mean daily temperature amplitudes as well as relative sunshine durations are above their long-term means; and, possibly due to reduced thunderstorm activity, the less pronounced zonal flow leads to negative deviations from summer mean wind speeds (Fig. 6c, shaded bars). Clearly, since summer weather in central Europe is mainly influenced by smaller-scale convective processes, the second canonical mode describes only a relatively small part of the interannual variability of the above mentioned variables (see also 'Model verification' below). Nonetheless, this mode can be interpreted to quantify for Bern the effects resulting from fluctuations in the intensity of the European summer monsoon (Schüepp \& Schirmer 1977).

\section{Model verification}

For all 5 variants of the SLP/near-surface temperature predictor data sets we determined per season and location, according to Eq. (4), the respective bestperforming 84 of 169 fitted CCA models. For each set

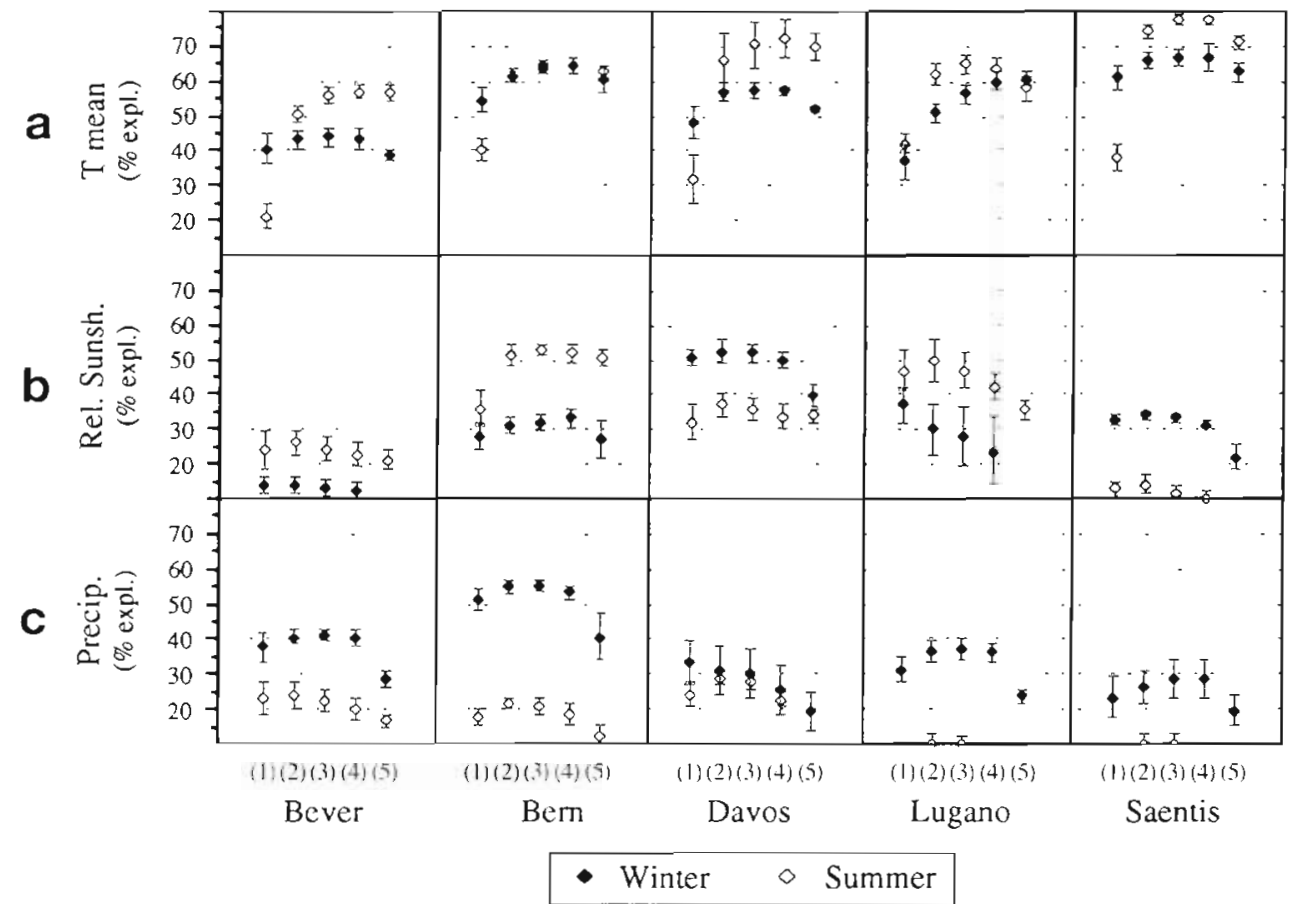

Fig. 7. Skill of the CCA models as a function of the predictor, season, location and variable considered. Shown are percentages of variances $\left(=100 \times \mathrm{r}^{2}\right)$ explained by the reconstruction of the weather statistics in the verification period 1941-1980. Data points denote the mean variance explained by 84 selected CCA models; error bars are \pm 1 standard deviation. From left to right (repeated for each location): (1) predictors were SLP anomalies alone; (2) predictors were SLP anomalies and near-surface temperature anomalies accounting for the total variance of the predictor data in the ratios $2: 1,(3) 1: 1$, and (4) $1: 2$; and (5) predictors were temperature anomalies alone 
of 84 CCA models, the models' capabilities to predict the individual weather statistics were assessed by comparing the statistically reconstructed interannual variations of the local variables with the observations. For 6 main weather statistics we also analysed the resulting 80 yr linear trends.

\section{Interannual variability}

The skill of the CCA models with regard to the individual variables was measured by the proportions of variance explained $\left(100 \times \mathrm{r}_{i}^{2}, i=1, \ldots, 84\right)$ in the verification period 1941-1980. Under the assumption of a normal distribution, correlations above 0.31 , i.e. skills above ca $10 \%$, suggest a statistically significant link to large-scale climate $(\alpha=95 \%)$.

Fig. 7 shows that the skill of the CCA models may vary strongly, depending on the large-scale predictors, the season, location, and weather statistic considered.

Though no combination of predictors could be found which yielded optimal results for all cases, the combined use of SLP and near-surface temperature generally improved the skill of the procedure (predictor data set variants 2 to 4 in Fig. 7). On average over all locations and variables, the mean variances explained when SLP (or near-surface temperature) alone was used, amounted to ca $23 \%$ (or $21 \%$ ) in winter and to $12 \%$ (or $18 \%$ ) in summer. An optimum was reached when the 2 fields were combined with equal weights, such that an average skill of $25 \%$ in winter and $19 \%$ in summer was attained. Use of the 2 predictors with equal weights seemed therefore to be a good compromise, which was maintained for the discussion below and for obtaining climatic change estimates from the GCM experiments.

As can be seen from Fig. 8, the most dramatic improvement occurred for the summer, and for temperature-related variables. However, the situation remained that most variables were better linked to the large-scale state of the atmosphere in winter than in summer.

In both seasons, better results were obtained at the 3 north alpine locations (Bern, Davos, Saentis) where, on average over all 3 locations and all variables, the mean skill of the CCA models amounted to $29 \%$ in winter and to $21 \%$ in summer. At the more southern locations (Bever, Lugano), on average only $20 \%$ (winter) and $17 \%$ (summer) were attained.

Large differences were found between the individual variables (Fig. 8). Temperatures were generally better reproduced than precipitation-related variables, the latter being particularly poorly predicted in summer. For seasonal mean temperatures, mean skills from the respective 84 selected CCA models were between $44 \%$ (Bever) and $67 \%$ (Saentis) in winter, and $56 \%$ (Bever) and $78 \%$ (Saentis) in summer (cf. Fig $7 \mathrm{a}$, data set variant 3). Mean daily temperature minima, which were better reproduced in summer than in winter at all locations except for Bern (not shown), were predicted with mean skills ranging from $30 \%$ (Lugano) to $64 \%$ (Saentis) in winter, and from 36\% (Lugano) to $73 \%$ (Saentis) in summer. Mean daily maximum temperatures were also generally well predicted, with skills ranging in winter from $59 \%$ (Bever)
Fig. 8. Comparison of skills between the procedure proposed by von Storch et al. (1993) (shaded bars) and the improved procedure (solid bars). Shown are mean percentages of explained variances (= $\left.100 \times \mathrm{r}^{2}\right)$ in the verification period 1941-1980 from all 5 case-study locations and all 84 selected CCA models fitted per season and location
Winter

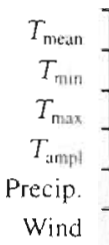

Rel. Hum.

Rel. Sunsh.

$s\left(T_{\text {mean }}\right)$

$S\left(T_{\text {mın }}\right)$

$s\left(T_{\text {nux }}\right)$

$s\left(T_{\text {ampl }}\right)$

s(Precip.)

$s$ (Wind)

s(Rel. Hum.)

s(Rel. Sunsh.)

$\mathrm{N}$ days precip.

$\geq 1 \mathrm{~mm}$

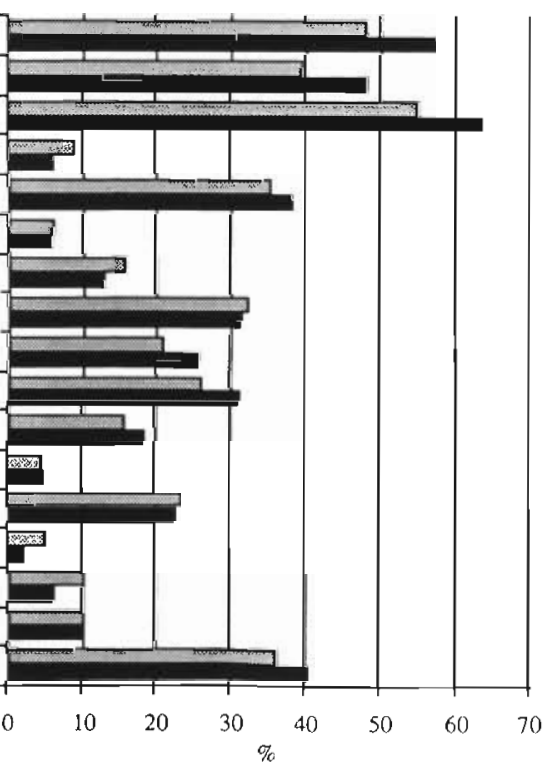

Summer

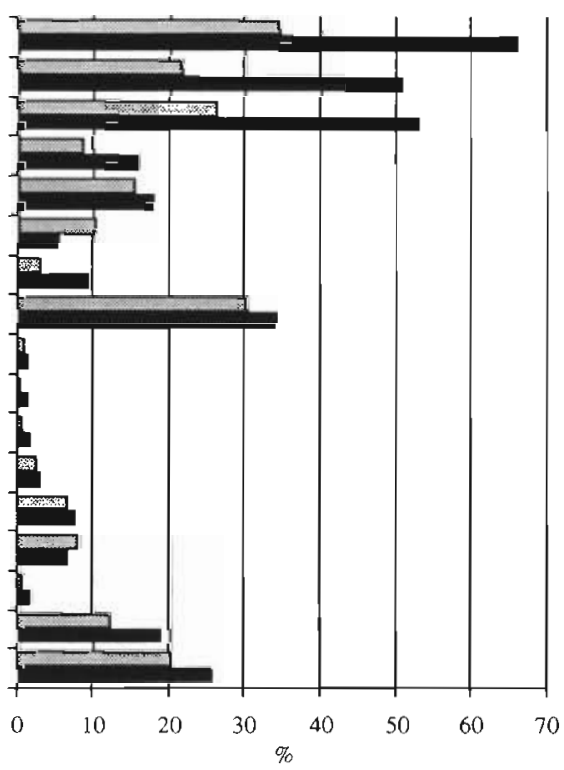

$\square$ SLP

SLP \& near-surface temperature 
to $69 \%$ (Bern), and in summer from $33 \%$ (Lugano) to $74 \%$ (Saentis). Mean daily temperature amplitudes were not well reproduced at any location in winter, but in summer skills of 19 , 24 and $32 \%$ were attained at Bever, Saentis and Bern, respectively. For precipitation, between $29 \%$ (Saentis) and $55 \%$ (Bern) were reached in winter, and between 10\% (Lugano, Saentis) and $28 \%$ (Davos) in summer (cf. Fig. $7 \mathrm{c}$ ). Relative sunshine durations, which directly depend on degree of cloudiness, were also less well reproduced; exceptions, however, were Davos $(52 \%)$ in winter and Bern $(53 \%)$ and Lugano (47\%) in summer (cf. Fig. 7b). Skills for the numbers of days with precipitation above $1 \mathrm{~mm}$ ranged from $29 \%$ (Davos) to $56 \%$ (Bern) in winter, and were $4 \%$ (Bever), $18 \%$ (Davos), 30\% (Saentis), 36\% (Lugano) and $42 \%$ (Bern) in summer. Seasonal mean wind speeds were not well predicted; the highest skills were attained in winter at Davos (18\%) and in summer at Saentis $(15 \%)$. Mean relative humidities were well reproduced only at Saentis in winter $(43 \%)$, whereas in summer at no location was more than $15 \%$ reached. Within-season standard deviations of daily mean, minimum and maximum temperatures were predicted in winter with skills between 20 and $45 \%$; an exception was Lugano, where skills for all 3 parameters were below $10 \%$, as was the case for all locations in summer. For the within-season standard deviations of daily precipitation totals, skills above $20 \%$ were reached at Bever $(24 \%)$, Bern (29\%) and Lugano (39\%) in winter, but again at no location in summer. From all remaining within-season standard deviations, a skill above ca. $20 \%$ was reached only for relative sunshine durations at Bern (21\%) and Davos $(20 \%)$ in winter and at Bever (19\%) and Lugano (52\%) in summer.

In Fig. 9, 5 yr running means of observed (thick lines) and reconstructed (grey areas) time series of weather statistics are compared, showing a generally coherent behavior between the pairs of curves. The better reproduction of temperatures (Fig. 9a, c) compared to precipitation-related variables (Fig. 9b,d) is also reflected in the different widths of the grey areas, i.e. the uncertainties resulting from different
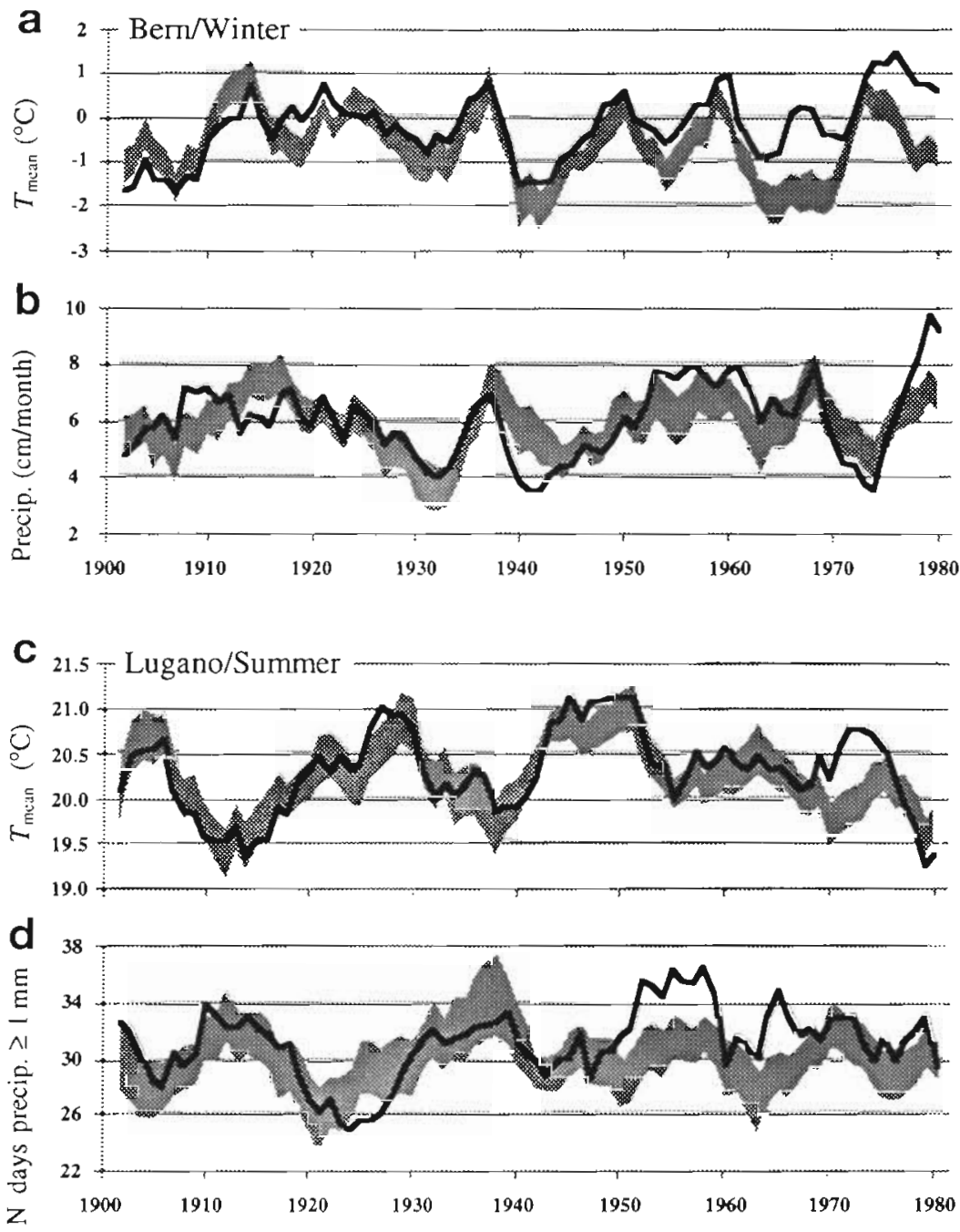

Fig. 9. Comparison of statistically reconstructed time series of local weather variables with observations ( 5 yr running means). Solid lines: observations, A models fitted separately for each season and location for the years (weights 1:1). Explained variances by the average time series (not shown) of the 84 CCA models in the verification period 1941-1980 were (a) $64 \%$, (b) $55 \%$, (c) $65 \%$ and (d) $36 \%$

choices in the numbers of EOFs used to fit the statistical models.

One main reason for the differences in the predictability of the local variables between the different locations, seasons and variables certainly is that our approach describes only the proportion of the interannual variability of a weather statistic which is controlled by fluctuations of large-scale SLP and nearsurface temperature. Differences may thus result from seasonally (winter vs summer) or regionally (northern vs southern Alps) varying intensities of smaller-scale convective activity, as well as from different combinations of local factors such as orography, vegetation, and soil characteristics. In particular, these factors may region- 
ally influence local wind systems, snow cover, or energy exchange with the atmosphere, thus uncoupling the variability of individual weather elements from the large-scale circulation. For example, seasonal mean minimum temperatures, which depend on smaller-scale thermal inversions and cold air drainage, were generally less well reconstructed than the seasonal mean and mean maximum temperatures. As could be expected, this was found to be particularly the case for the 4 valley locations, and for the winter season.

It should be noted that the inclusion of 17 not equally well cross-correlated variables within the same CCA model tended to worsen the prediction of individual variables to the benefit of the ensemble. This is because - despite the standardisation of all predictands to the unit standard deviation (Fig. 3) - the relative importance of individual variables was implicitly influenced by typical correlation structures found in the predictand data sets, e.g. a clustering of temperature- or precipitation-related variables. Possibly, by an alternative choice or weighting of the predictands, the modest performance obtained for e.g. mean relative humidities and wind speeds could be improved.

\section{Long-term linear trends}

The observed and reconstructed 1901-1980 linear trends of 6 main weather statistics are summarised in Table 2.
Seasonal daily mean, mean minimum and mean maximum temperatures displayed an upward trend at all 5 stations in winter. The CCA models uniformly failed to reproduce any signs of these trends and instead indicated a decrease in temperature since the beginning of this century. With respect to the interannual variations, however, the similarity between reconstructed time series and the in situ observations was much greater (Fig. 9a). A similar finding was reported by Werner \& von Storch (1993).

CCA indicated a net cooling because of a large-scale trend in SLP (Fig. 10a), whereas the spatially less homogeneous trend in the Vinnikov (1986) temperature data (Fig. 10b) did not affect the reconstruction of the temperature trends much (see also Eq. 1). The reality of the long-term SLP trend was documented by von Storch et al. (1993), who found a consistent signal in both ship-of-opportunity observations of SLP and in in situ precipitation records on the Iberian Peninsula. When only SLP was used for CCA, the discrepancy between the CCA models and the local observations was increased mean \pm standard deviation of the trend from 84 selected CCA models for winter mean temperature in Bern: $-1.21 \pm 0.28^{\circ} \mathrm{C}$ per $80 \mathrm{yr}$ ). The differences between the $80 \mathrm{yr}$ trends also remained when the 1941-1980 interval was used to fit the CCA models.

There are several candidates that may account for part or all of the discrepancy:

First, the effect of the systematically changing pressure field on the Swiss temperature must have been counteracted by another large-scale feature, presum-

Table 2. Mean linear trends of weather statistics in the period 1901-1980, both observed (Obs.) and reconstructed (Rec.) from 84 selected CCA models. The CCA models were fitted for the years 1901-1940 to a combined SLP/near-surface temperature predictor data set (weights 1:1). Quantities are given in respective units per $80 \mathrm{yr}$; asterisks denote significance of trends at the $95 \%$ level (given for observations only). LTM: long-term (1901-1980) mean

\begin{tabular}{|c|c|c|c|c|c|c|c|c|c|c|}
\hline \multirow{2}{*}{ Seasonal statistics } & \multicolumn{2}{|c|}{ Bever } & \multicolumn{2}{|c|}{ Bern } & \multicolumn{2}{|c|}{ Davos } & \multicolumn{2}{|c|}{ Lugano } & \multicolumn{2}{|c|}{ Saentis } \\
\hline & Obs. & Rec. & Obs. & Rec. & Obs. & Rec. & Obs. & Rec. & Obs. & Rec. \\
\hline \multicolumn{11}{|l|}{ Winter } \\
\hline$T_{\text {mean }}\left({ }^{\circ} \mathrm{C}\right)$ & 0.78 & -0.51 & $1.34^{\circ}$ & -0.49 & $1.75^{\circ}$ & -0.53 & $1.17^{\circ}$ & -0.47 & 0.63 & -0.99 \\
\hline$T_{\min }\left({ }^{\circ} \mathrm{C}\right)$ & 1.16 & -0.34 & $2.36^{\circ}$ & -0.43 & $2.64^{\circ}$ & -0.44 & $2.00^{\circ}$ & -0.46 & 0.52 & -1.03 \\
\hline$T_{\max }\left({ }^{\circ} \mathrm{C}\right)$ & 0.60 & -0.56 & 0.36 & -0.76 & 0.77 & -0.59 & 0.44 & -0.77 & 0.82 & -0.98 \\
\hline Rel. sunsh. (\%) & $-11.6^{*}$ & -2.1 & -3.1 & -3.4 & -6.2 & -4.2 & -6.0 & -4.5 & -0.9 & -2.2 \\
\hline Precip. (\% of LTM) & -20.9 & 7.4 & 16.3 & 6.6 & 12.2 & 0.5 & 28.4 & 18.1 & $-47.4^{\circ}$ & -2.7 \\
\hline $\begin{array}{l}\mathrm{N} \text { days } \geq 1 \mathrm{~mm} \\
(\% \text { of } \mathrm{LTM})\end{array}$ & -9.3 & 8.0 & 2.6 & 3.6 & 5.2 & 6.2 & 27.8 & 20.9 & -9.4 & 3.4 \\
\hline \multicolumn{11}{|l|}{ Summer } \\
\hline$T_{\text {mean }}\left({ }^{\circ} \mathrm{C}\right)$ & -0.01 & 0.25 & 0.50 & 0.02 & 0.05 & 0.04 & 0.22 & -0.09 & 0.69 & 0.16 \\
\hline$T_{\text {min }}\left({ }^{\circ} \mathrm{C}\right)$ & 0.27 & 0.21 & $1.24^{\circ}$ & 0.18 & $1.22^{\circ}$ & 0.13 & $2.13^{\circ}$ & 0.03 & 0.61 & 0.19 \\
\hline$T_{\max }\left({ }^{\circ} \mathrm{C}\right)$ & -0.58 & 0.60 & -0.25 & -0.12 & -0.21 & -0.06 & -2.21 & -0.23 & 0.80 & 0.17 \\
\hline Rel. sunsh. $(\%)$ & $-5.1^{\circ}$ & -1.6 & $-6.6^{\circ}$ & -0.6 & $-7.3^{\circ}$ & -1.2 & $-10.3^{\circ}$ & -0.7 & $6.0^{\circ}$ & 0.2 \\
\hline Precip. $(\%$ of LTM) & 7.1 & 5.8 & 1.1 & -0.8 & -1.7 & -1.2 & -5.4 & 4.7 & -16.2 & -4.9 \\
\hline $\begin{array}{l}N \text { days } \geq 1 \mathrm{~mm} \\
(\% \text { of } \mathrm{LTM})\end{array}$ & 0.9 & 0.5 & -3.1 & -0.6 & -0.3 & -1.2 & 9.7 & 1.4 & -0.1 & -3.3 \\
\hline
\end{tabular}


a

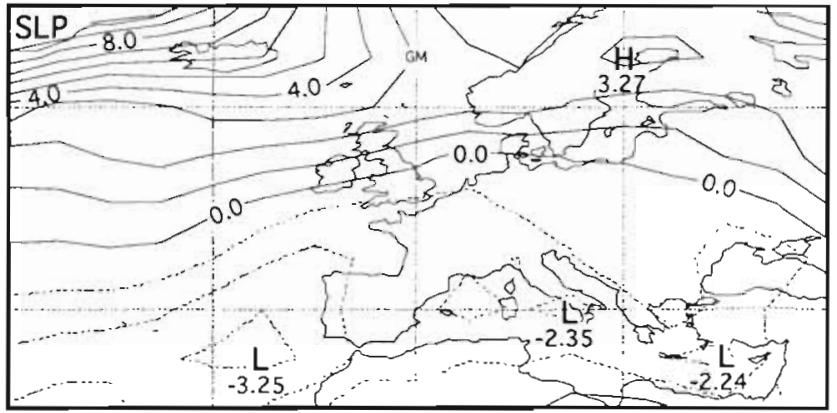

b

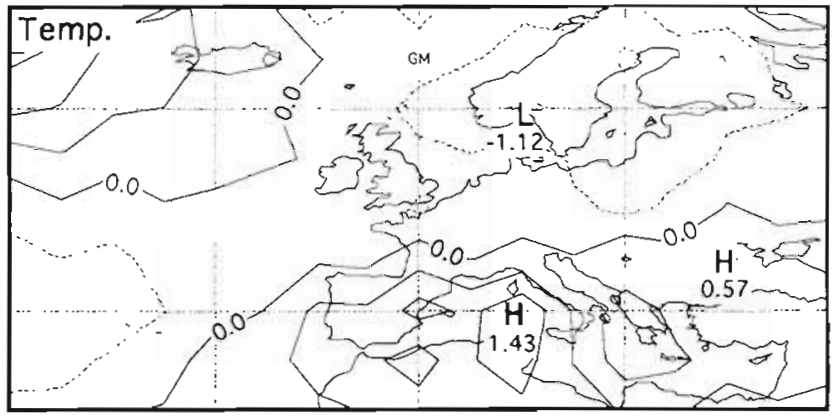

Fig. 10. 1901-1980 linear trends in the data sets used for (a) winter mean SLP (contour interval 1 mb) and (b) winter mean nearsurface temperature (contour interval $0.5^{\circ} \mathrm{C}$ )

ably representing the thermal structure of the troposphere. One possibility is that, e.g. due to the use of changing reference intervals, a real trend in near-surface temperature is not correctly represented in the Vinnikov data set. Preliminary calculations with the Jones data set (Jones \& Briffa 1992, Briffa \& Jones 1993) actually yielded less negative 80 yr trends for winter mean temperatures, but only by 0.1 to $0.3^{\circ} \mathrm{C}$. An alternative explanation could thus be that there is a trend in a large-scale parameter not included in our analysis, e.g. $500 \mathrm{mb}$ geopotential height. Due to the lack of data in the first half of this century, however, this hypothesis could not be tested.

A second reason could be that the statistical link between the local temperatures and the large-scale circuiation has changed with time. For example, systematic changes in the frequencies of short-lived weather systems, which have a strong effect on the local temperatures, may not be adequately represented in the seasonal mean fields. Possibly, the linear CCA models may also have failed to capture any non-linear effects.

Third, it should be noted that the positive trends are significant only for the seasonal mean and mean minimum temperatures at the 3 urban stations, whereas the 2 rural stations Bever and Saentis show much smaller trends (Table 2). From Fig. 9a it becomes obvious that the CCA models failed to reproduce the trend not only in the last $40 \mathrm{yr}$ of the verification interval but also in the first $40 \mathrm{yr}$ of the analysis interval. We speculate that the positive trends at the urban stations are overestimated due to the urban heat island effect and increasing air pollution.

In summer, the discrepancy between the indirectly derived and the in situ trends of the 3 temperature parameters was considerably smaller than in winter Only the trends of the mean minimum temperatures at the 3 urban stations were not reproduced. We suggest that these in situ records are contaminated by a significant urbanisation effect. Another major difference was found at Lugano, where the in situ observations of seasonal mean daily temperature maxima indicate a net cooling of $-2.2^{\circ} \mathrm{C}$, whereas the large-scale field specified a small cooling of only $-0.2^{\circ} \mathrm{C}$.

For relative sunshine in winter the statistical models were more successful in reproducing the sign of the trends, even if the absolute values deviated somewhat. The significant reduction in relative sunshine obtained for Bever, as well as its poor reproduction by the CCA models (Fig. 7b), probably occurs because measurements for this location were taken from the climate station of St. Mortis $6.9 \mathrm{~km}$ away, which furthermore has often been moved.

Trends in summer mean relative sunshine durations were generally underestimated by CCA, but the signs were correct in all 5 cases. The largest deviations were found for Lugano, where relative sunshine decreased during 1901-1980 by more than 10\%, whereas the CCA models estimated a reduction by only $0.7 \%$. Again, this discrepancy could be due to the climate station's being moved (H. Bantle, SMA, pers. comm.) or to increased air pollution (see also Gensler 1978, p. 9).

Trends of daily mean precipitation and of number of days with precipitation exceeding $1 \mathrm{~mm}$ were mostly reproduced with an error remaining within $10 \%$ of the respective 1901-1980 long-term means. At Bever, observed $(-21 \%)$ and reconstructed $(+7.4 \%)$ winter precipitation trends were not consistent, but both numbers are small compared to the 1901-1980 standard deviation, which amounts to ca $49 \%$ of the long-term mean. The significant trend found for mean winter precipitation in Saentis, which was also not well reconstructed by means of CCA, is doubtful, since precipitation may not be reliably measured at this peak location.

\section{Downscaling of GCM-simulated climatic changes}

GCM-simulated predictors for the climatic change experiments performed with the ECHAM1/LSG GCM were derived as deviations from the mean SLP and 
near-surface temperature fields simulated in the first $40 \mathrm{yr}$ of the 'control' run. The 'control' run shows a drift in the globally and annually averaged near-surface temperature of less than $-0.4^{\circ} \mathrm{C}$ in $100 \mathrm{yr}$, which may be attributed to low-frequency variability of the model. In the $\mathrm{DCO}_{2}$ experiment, after 1 century temperature has increased by $1.7^{\circ} \mathrm{C}$. In the SCNA experiment, global mean temperature rises during the first 40 yr by a moderate $0.5^{\circ} \mathrm{C}$, which is likely an underestimate due to the 'Cold Start' problem (see Hasselmann et al. 1992). The rate of temperature growth increases then to $0.35^{\circ} \mathrm{C}$ per decade, such that by the year 2085 , and under greenhouse gas concentrations of ca 1150 ppm equivalent $\mathrm{CO}_{2}$, global warming reaches $2.6^{\circ} \mathrm{C}$. This result lies between the lowest and best estimates of approximately 2 and $3{ }^{\circ} \mathrm{C}$, respectively, given for the same future timepoint by Houghton et al. (1990).

Fig. 11 shows time-dependent changes in the temperature and precipitation statistics of Bern, downscaled from the SLP and near-surface temperature anomaly fields of the $100 \mathrm{yr}$ SCNA experiment. The range of values predicted by the different CCA models using different numbers of EOFs typically increases with time, i.e. with the magnitude of large-scale climatic change. This is because differences in the regression coefficients of Eq. (3) become increasingly effective the more the predictors deviate from the mean state used for CCA model estimation.

In Figs. 12 \& 13 projected changes in seasonal temperature and precipitation parameters are compared between locations. The regional differentiation obtained is in strong contrast to the homogeneous changes specified at single GCM gridpoints on a spatial scale of several $10^{2} \mathrm{~km}$. During the last decade of the SCNA experiment, the projected temperature deviations dif- fer between locations by as much as $1.8^{\circ} \mathrm{C}$ in winter and $2.0^{\circ} \mathrm{C}$ in summer. Similarly pronounced differences occurred for most other variables as well (e.g. Fig. 13).

As can be seen from Fig. 12, the $\mathrm{DCO}_{2}$ and SCNA experiments yielded similar patterns of change between the different locations. Since this was not only the case for temperature (see also Table 3), we will focus below on the last decade of the SCNA experiment, where the most pronounced changes occurred. Further, since for some variables the downscaled changes strongly depended on the data used for CCA model estimation (Fig. 13), the mean responses of CCA models fitted in the period 1901-1940, as well as in the complementary period 1941-1980 will be considered.

The results for 6 main variables are summarised in Table 3. For seasonal mean temperatures, the 'best estimates' - i.e. the mean changes from all used CCA models per season and location - amounted to $2.0^{\circ} \mathrm{C}$
Fig. 12. Statistically downscaled changes in seasonal mean temperatures for the last $20 \mathrm{yr}$ of the 'double $\mathrm{CO}_{2}$ ' $\left(\mathrm{DCO}_{2}\right)$ experiment and for the last $10 \mathrm{yr}$ of the 'IPCC Scenario A' experiment. Shown are the mean changes obtained from 84 selected CCA models fitted in the period 1901-1940 separately for each season and location. Changes are given relative to the 1901-1940 means
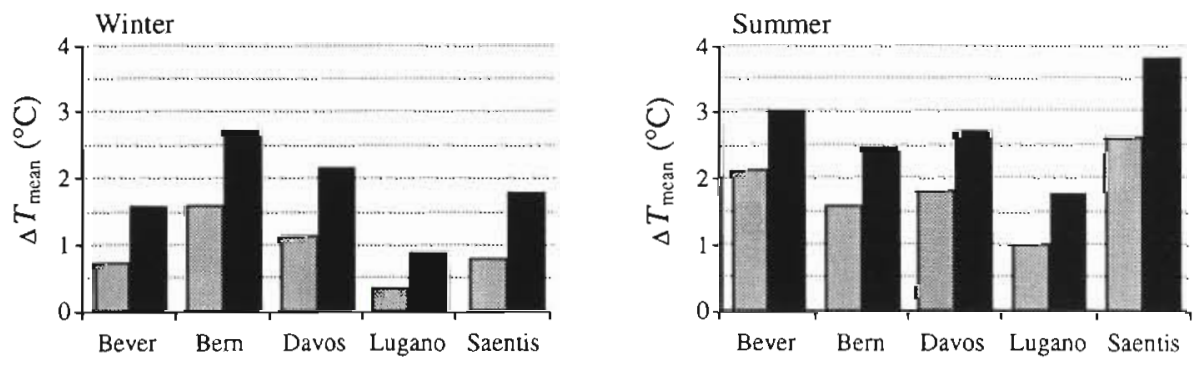

[.․․ $\mathrm{DCO}_{2}$ 

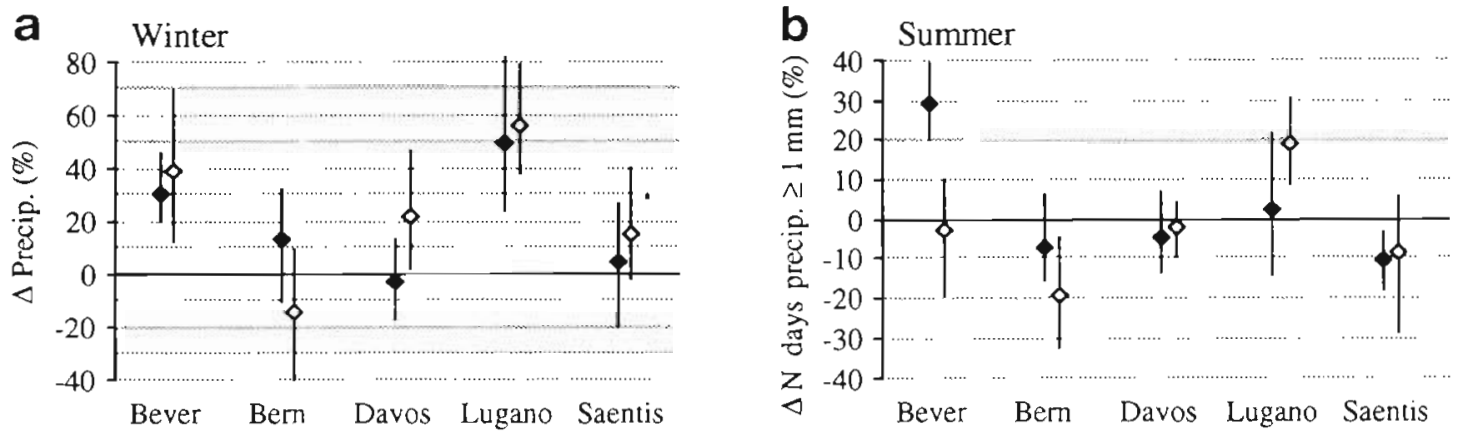

$$
\text { CCA: 1901-40 } \diamond 1941-80, \quad \text { Scenario A }
$$

Fig. 13. Statistically downscaled changes in (a) winter precipitation totals and (b) summer probabilities of days with precipitation $\geq 1 \mathrm{~mm}$, for the last $10 \mathrm{yr}$ of the 'IPCC Scenario A' experiment. The CCA models were fitted in the periods 1901-1940 (solid points) and 1941-1980 (open points), respectively. Data points indicate mean changes obtained from a set of 84 selected CCA models fitted separately for each period, season and location; error bars denote the empirical intervals containing $90 \%$ of the respective CCA model responses. Changes are given relative to the 1901-1980 means

in winter and $2.4^{\circ} \mathrm{C}$ in summer, averaged over the 3 northern locations Bern, Davos and Saentis, and to $1.2^{\circ} \mathrm{C}$ in winter and $2.7^{\circ} \mathrm{C}$ in summer, averaged over the 2 southern locations Bever and Lugano. Winter mean daily temperature extremes showed similar spatial patterns of change to the winter temperature means: winter mean daily minimum temperatures were found to rise at the northern (southern) slope of the Alps by an average $2.2^{\circ} \mathrm{C}\left(1.5^{\circ} \mathrm{C}\right)$, whereas for the maxima moderate changes of $1.8^{\circ} \mathrm{C}\left(1.0^{\circ} \mathrm{C}\right)$ occurred. Warming was very differently distributed in summer, where a substantial increase by $3.1^{\circ} \mathrm{C}\left(3.9^{\circ} \mathrm{C}\right)$ was obtained for the temperature maxima, as opposed to only $2.6^{\circ} \mathrm{C}\left(1.7^{\circ} \mathrm{C}\right)$ for the temperature minima. Projected changes in relative sunshine durations were generally small for winter, whereas in summer changes of $+36 \%$ were specified at the northern, and $+17 \%$ and the southern slope of the Alps. Winter precipitation totals changed by only ca $+6 \%$ at the northern locations, but increased dramatically by $34 \%$ (Bever) and 53\% (Lugano) at the more southern ones (see also Fig. 13a). Summer precipitation was found to increase at all locations by 4 to $30 \%$, except for Saentis, where a strong decrease of $42 \%$ was specified; the strongest increase occurred again at the southern slope of the Alps (average $26 \%$ ). Winter probabilities of wet days did not change much at the 3 northern locations, whereas at Bever it increased by $15 \%$ and at Lugano by $28 \%$; summer probabilities of wet days were found to change at the 3 northern locations by -3 to $-13 \%$ and, again, to increase at the 2 southern locations by an average of ca $12 \%$ (see also Fig. 13b).

The following 'best estimates' were obtained for the weather statistics not considered in Table 3. Seasonal mean daily temperature amplitudes decreased in winter quite uniformly by an average of $-0.4{ }^{\circ} \mathrm{C}_{i}$ in summer they increased at the 3 northern locations by $0.5^{\circ} \mathrm{C}$ on average, and at the 2 southern locations by $2.2^{\circ} \mathrm{C}$. Winter daily mean wind speeds were found to decrease at Bever by $48 \%$ and at Davos by $40 \%$, and to increase at Lugano by $9 \%$, of the respective longterm mean; in summer, mean wind speeds decreased again at Bever $(-75 \%)$ and Davos $(-64 \%)$, but increased by $35 \%$ at Bern and $61 \%$ at Lugano. Seasonal mean relative humidities did not change much in both seasons at all locations, except for Saentis in summer $(-15 \%)$. Within-season standard deviations of daily mean, minimum and maximum temperatures decreased systematically at all locations, on average by 21, 21 and $18 \%$ in winter and by 11,10 and $7 \%$ in summer, respectively. Within-season standard deviations of daily temperature amplitudes were generally reduced in winter, by ca $10 \%$, whereas in summer less coherent changes among the locations, in the order of $\pm 10 \%$, were obtained. Within-season standard deviations of daily precipitation totals increased in winter at Bever and Lugano by 40 and $46 \%$, respectively, and in summer by 5 to $24 \%$ at all locations, except for Saentis, where a reduction by $41 \%$ occurred. Withinseason standard deviations of daily relative sunshine durations changed in winter only at Saentis $(+10 \%)$, whereas in summer they increased at Saentis $(+74 \%)$ as well as at Bever $(+10 \%)$, and decreased by 5 to $10 \%$ at the remaining locations.

The procedure yielded not only a regionally differentiated but also an internally consistent picture of possible climatic change. Note that plausible changes were even obtained for several variables which were not well predicted in the model verification phase. In a few cases, however, e.g. for summer precipitation and 


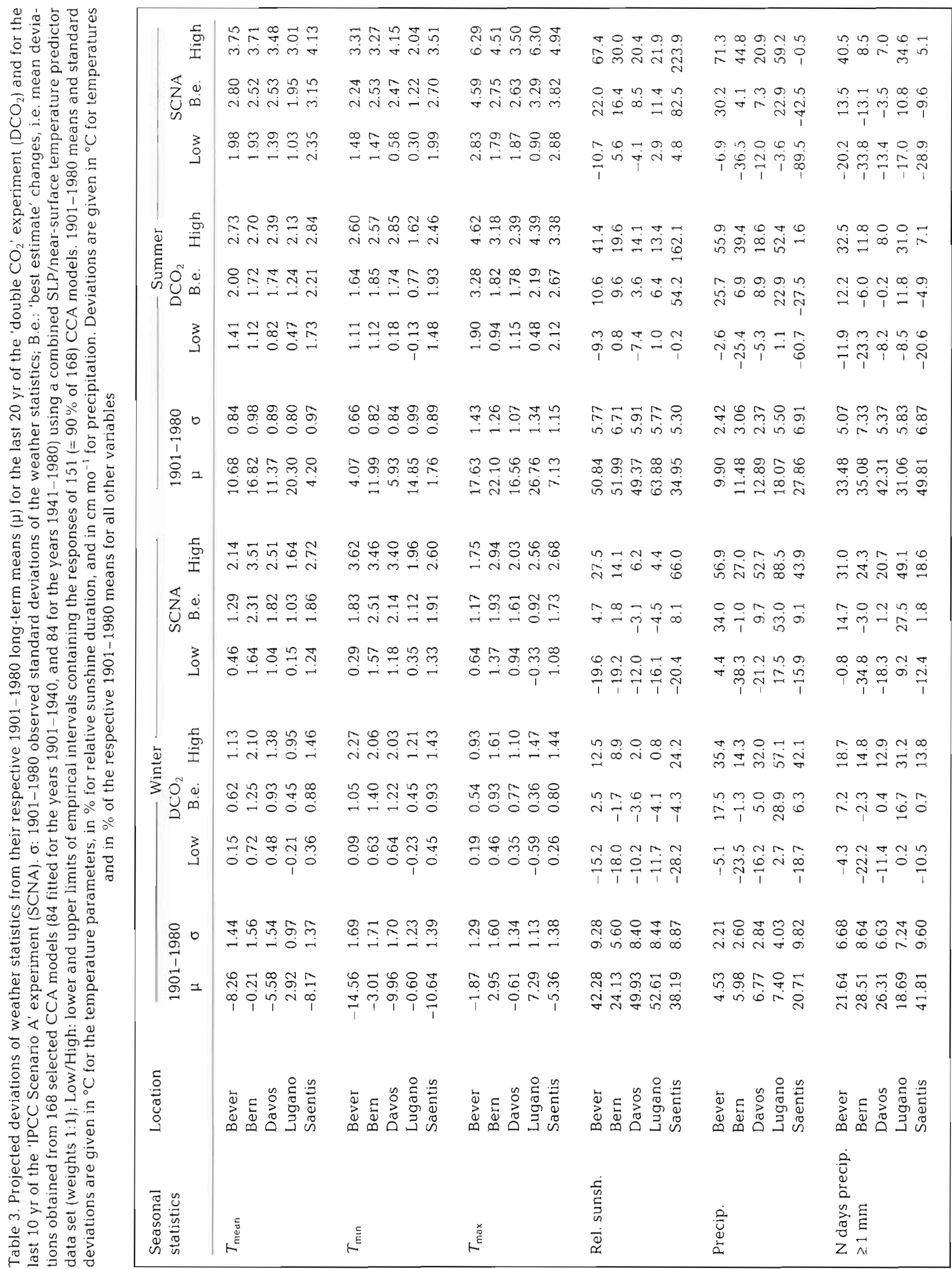


mean relative sunshine duration at Saentis, the CCA models did not yield sensible results. Possible reasons could be that the linearity assumption (Eq. 3) was violated, or that inconsistencies in the local data sets were amplified under the given large-scale climatic change. All in all, winter climate was predicted to be milder and wetter than under present conditions. This suggests an increased probability for nighttime cloud cover, which is consistently mirrored in a stronger rise of the minimum as compared to the maximum temperatures, a general decrease of mean daily temperature amplitudes, and a smaller within-winter temperature variability. The summer was predicted to become generally hotter and wetter; in this connection, strong increases in relative sunshine durations, mean daily maximum temperatures and temperature amplitudes suggested increased irradiation and surface heating. The increases in summer precipitation could correspond to stronger convective activity or to more intense intrusions of maritime air, which would compensate for the more pronounced ocean-continent temperature contrast as simulated by the GCM. In both seasons, the precipitation increases consistently tended to occur with increased within-season variabilities of daily precipitation totals and increased probabilities of wet days.

It should be noted that the large-scale signals underlying the responses of all weather statistics (Eq. 1') were found, in both seasons and for all locations, to be mainly determined by the rising near-surface temperature. In particular, the projected changes depended strongly on the inclusion of near-surface temperature as a largescale predictor. For example, when SLP was used as the only predictor in winter, anomalously high SLP between $35^{\circ}$ and $50^{\circ} \mathrm{N}$ in the final decade of the SCNA experiment implied precipitation decreases by 4 to $12 \%$ in Bever, Bern and Lugano, and positive changes of a few percent in Saentis and Davos. Yet in Fig. 12a precipitation increases are shown which, since they include the information for the temperature field, can be interpreted to be a consequence of the higher moisture content of the air advected towards the Alps, counterbalancing the effect of slightly weakened westerlies. It is possible that inclusion of additional predictors which show similarly drastic changes to those of near-surface temperature in the GCM, e.g mid-tropospheric pressure fields, could further modify our results.

The downscaled climatic changes strongly reflected the characteristics of the underlying GCM simulation. The $\mathrm{DCO}_{2}$ and SCNA experiments yielded qualitatively similar changes in local climates (Fig 12, Table 3) because the GCM's large-scale responses for SLP (not shown), as well as for near-surface temperature (Cubasch et al. 1992), to the respective greenhouse gas forcings show quite similar large-scale patterns in both experiments. In the case of the SCNA experiment, the small changes projected for the first 50 yr of the scenario period (Fig. 11) reflect the delayed global mean temperature response of the ECHAM1/LSG GCM. Further, the GCM-downscaled year-to-year fluctuations of the weather statistics were generally smaller than under the present climate (Fig. 9 vs Fig. 11). This is due to a systematic underestimation of the interannual variability of seasonal mean SLP by the GCM which occurs in the 'control' run as well as in the first decades of the SCNA experiment for both seasons considered (not shown). A possible reason for this could be the underestimation of mid-latitude cyclonic activity resulting from the model's low spatial resolution (cf. Cubasch et al. 1992). Finally, it should be noted that the smallest warming occurred for both seasons at the southern slope of the Alps (Lugano). This is possibly because temperatures at the north alpine locations (Bern, Davos and Saentis) and at the more eastwardly located Bever are more strongly determined by advection from higher latitudes and northeastern Europe, which are the regions where the largest warming takes place in the GCM.

\section{CONCLUSIONS}

From our case studies at the 5 representative locations in the Alps we conclude

(1) It is possible to establish plausible statistical relationships which allow the large-scale climatic changes produced by GCMs to be linked to local ecosystem model inputs, even in a complex orography like the Alps. The results obtained were meaningful for winter (Dec, Jan, Feb) as well as for summer (Jun, Jul, Aug). For each location, the statistical models quantified the effects resulting from changes in major circulation patterns, e.g. from changes in the strengths of large-scale zonal or meridional flow or of subsidence, and from fluctuations in the associated largescale near-surface temperature distributions.

(2) The strength of the statistical link to the largescale circulation depends on the season, location, and variable considered. The procedure allows several important ecosystem inputs to be reconstruced on a yearly to decadal timescale reasonably well.

The most reliably reconstructed variables were seasonal daily mean, mean minimum and mean maximum temperatures, whereas the poorest results were obtained for daily mean temperature amplitudes, relative humidities, wind speeds, and, for summer only, daily precipitation totals and number of days with precipitation above $1 \mathrm{~mm}$, plus most within-season standard deviations of daily variables. Some observed 80 yr trends, especially for mean daily temperatures and 
temperature extremes in winter and for mean minimum temperatures in summer, could not be correctly reproduced. On the whole, most variables were better reconstructed in winter than in summer.

On average over all variables, the 3 north alpine locations (Bern, Davos and Saentis) could be better linked to large-scale climate than the 2 more southern locations (Bever, Lugano). This difference was more pronounced in winter than in summer.

(3) The downscaling procedure originally proposed by von Storch et al. (1993) could be improved by including large-scale near-surface temperature anomalies as an additional large-scale predictor. Improvement was possible for almost all variables and generally for all locations considered in this study. The largest improvements were found for seasonal mean temperatures and mean daily temperature extremes, and for the summer season.

(4) The method presented here allows regionally differentiated, time-dependent climatic change estimates to be flexibly derived for input variables required by ecosystem models at a much smaller spatial scale than given by the resolution of present GCMs.

However, the following restrictions of this approach must not be overlooked:

- Considerable amounts of data must be available and have to be managed. Required are sufficiently long records of the local variables close enough to the location of interest, simultaneous observations of the large-scale state of the atmosphere in the sector containing this location, as well as corresponding data sets from experiments with GCMs.

- The method assumes that the established statistical relationships also remain valid under future climatic conditions. For example, towards the end of the SCNA experiment the GCM-simulated fields undergo changes which exceed the range of the observations used to fit the statistical models; thus, towards the end of the next century the projected changes in the local variables represent (linear) extrapolations which might not necessarily hold in the real world.

- The downscaled local climatic changes will not be more reliable than the underlying GCM experiments. For example, the relatively modest temperature increases obtained in our study at all locations are a consequence of the relatively low sensitivity of the ECHAM1/LSG GCM to increased greenhouse gas concentrations. Local climatic changes should therefore be explored for experiments with other GCMs, a procedure which is easy to accomplish with our method.

In spite of these difficulties, the proposed method represents to our knowledge the best approach cur- rently available to consistently link GCM-simulated climatic changes to ecosystem models. In combination with stochastic weather generators it can be used to derive multivariate climatic change scenarios on a wide range of temporal scales, and yet it allows the high spatial detail particularly required within a mountainous region to be attained. Moreover, our approach can be easily adapted to the specific needs emerging from ongoing ecosystem research. Yet further improvements can be envisaged, e.g. by downscaling only a reduced set of inputs, by using additional large-scale predictors and, as recent work showed (Gyalistras \& Fischlin 1994), by spatial inter- and extrapolation to points with scanty or even no measurements.

Acknowledgements. The authors thank E. Zorita (MPI) for discussions on concepts and methodology; E. Zorita and I. Jessel for help with the global data sets; H. Borgert (MPI) for his patience and technical assistance; H. Bantle (SMA) and G. M. Sigut (RZ ETHZ) for supporting the extraction of Swiss climate data; $M$. Schüepp and $A$. de Montmollin (SMA) for information on station history and data quality. This work was supported by the Swiss National Science Foundation, grant nos 21-31134.91 and 5001-036812 (Swiss Priority Program Environment).

\section{LITERATURE CITED}

Anderson, C. W. (1984). An introduction to multivariate statistical analysis, 2nd edn. Wiley \& Sons, New York

Bantle, H. (1989). Programmdokumentation Klima-Datenbank am RZ-ETH Zürich. Schweizerische Meteorologische Anstalt, Zürich

Barnett, T., Preisendorfer, R. (1987). Origins and levels of monthly and seasonal forecast skills for United States surface air temperatures determined by canonical correlation analysis. Mon. Weather Rev. 15: 1825-1850

Briffa, K. R., Jones, P. D. (1993). Global surface air temperature variations during the twentieth century: Part 2, Implications for large-scale, high-frequency paleoclimatic studies. Holocene 3: 77-88

Brzeziecki, B., Kienast, F., Wildi, O. (1993). Simulated map of the potential natural forest vegetation of Switzerland. J. Veg. Sci. 4: 499-508

Bugmann, H., Fischlin, A. (1992). Ecological processes in forest gap models - analysis and improvement. In: Teller, A., Mathy, P., Jeffers, J. N. R. (eds.) Responses of forest ecosystems to environmental changes. Elsevier Applied Science, London, p. 953-954

Bugmann, H., Fischlin, A. (1994). Comparing the behaviour of mountainous forest succession models in a changing climate. In: Beniston, M. (ed.) Mountain environments in changing climates. Routledge, London, p. 204-219

Cubasch, U., Hasselmann, K., Höck, H., Maier-Reimer, E., Mikolajewicz, U., Santer, B. D., Sausen, R. (1992). Timedependent greenhouse warming computations with a coupled ocean-atmosphere model. Clim. Dynam. 8: 55-69

Dickinson, R. E. (1986). How will climate change? The climate system and modelling of future climate. In: Bolin, B., Döös, B. R., Jäger, J., Warrick, R. A. (eds.) The greenhouse effect, climatic change and ecosystems. SCOPE Vol. 29. Wiley, Chichester, p. 206-270 
Ehrendorfer, M. (1987). A regionalization of Austria's precipitation climate using principal component analysis. J. Climatol. 7: 71-89

Fischlin, A. (1982). Analyse eines Wald-Insekten-Systems: der subalpine Lärchen-Arvenwald und der graue Lärchenwickler Zeiraphera diniana Gn. (Lep., Tortricidae). Dissertation No. 6977, Swiss Federal Institute of Technology, Zürich

Fischlin, A., Bugmann, H., Gyalistras, D. (1995). Sensitivity of a forest ecosystem model to climate parametrization schemes. Environ. Pollut. 87(3): 267-282

Flohn, H., Fantechi, R. (eds.) (1984). The climate of Europe: past, present and future. D. Reidel, Dordrecht

Gates, W. L., Mitchell, J. F. B., Boer, G. J., Cubasch, U., Meleshko, V. P. (1992). Climate modelling, climate prediction and model validation. In: Houghton, J. T., Callander, B. A., Varney, S. K. (eds.) Climate change 1992 - the supplementary report to the IPCC scientific assessment. Cambridge University Press, Cambridge, p. 97-134

Gates, W. L., Rowntree, P. R., Zeng, Q.-C. (1990). Validation of climate models. In: Houghton, J. T., Jenkins, G. J., Ephraums, J. J (eds.) Climate change - the IPCC scientific assessment. Report prepared for IPCC by Working Group 1. Cambridge University Press, Cambridge, p. 99-137

Gensler, G. A. (1978). Das Klima von Graubünden: ein Beitrag zur Regionalklimatologie der Schweiz. Arbeitsberichte der Schweizischen Meteorologischen Zentralanstalt, No. 77, Zürich

Giorgi, F., Marinucci, M. R., Visconti, G. (1990). Application of a limited area model nested in a general circulation model to regional climate simulation over Europe. I geophys. Res. 95: 18413-18431

Giorgi, F., Mearns, L. O. (1991). Approaches to the simulation of regional climate change: a review. Rev. Geophys. 2 $191-216$

Glahn, H. R. (1985). Statistical weather forecasting. In Murphy, A. H., Katz, R. W. (eds.) Probability, statistics and decision making in the atmospheric sciences. Westview Press, Boulder, CO, p. 289-366

Gyalistras, D., Fischlin, A. (1994). Derivation of climatic change scenarios for mountainous ecosystems: a GCMbased method and the case study of Valais, Switzerland Systems Ecology Group, Swiss Federal Institute of Technology, Report Nr. 19, Zürich

Hasselmann, K, Sausen R, Maier-Reimer, E., Voss, R. (1992) On the cold start problem in transient simulations with coupled ocean-atmosphere models. MPI Report No. 83 Max-Planck-Institut für Meteorologie, Hamburg

Houghton, J. T., Jenkins, G. J., Ephraums, J. J. (eds.) (1990). Climate change - the IPCC scientific assessment. Report prepared for IPCC by Working Group 1. Cambridge University Press, Cambridge

Hulme, M., Wigley, T.M.L., Jones, P.D. (1990). Limitations of regional clmate scenarios for impact analysis. In: Boer, M. M., de Groot, R. S. (eds.) Landscape-ecological impact of climatic change. IOS Press, Amsterdam, $p$. $111-129$

Jessel, I. (1991). Inventory of available observed data sets. Tech. Rep. No. 1, Deutsches KLimarechenzentrum GmbH, Hamburg

Jones, P. D., Briffa, K. R. (1992). Global surface air temperature variations during the twentieth century: Part 1, Spatial, temporal and seasonal details. Holocene 2: 165-179

Karl, T. R., Wang, W.-C., Schlesinger, M. E., Knight, R. W. Portman, D. (1990). A method relating General Circulation
Model simulated climate to the observed local climate Part I: Seasonal statistics. J. Clim. 3: 1053-1079

Kim, J. W., Chang, J. T., Baker, N. L., Wilks, D. S., Gates, W. L. (1984). The statistical problem of climate inversion: determination of the relationship between local and large-scale climate. Mon. Weather Rev. 112: 2069-2077

Kreyszig, E. (1977). Statistische Methoden und ihre Anwendungen. Vandenhoeck \& Ruprecht, Göttingen

Kutzbach, J. E. (1967). Empirical eigenvectors of sea-level pressure, surface temperature and precipitation complexes over North America. J. appl. Meteorol. 6: 791-802

Lischke, H., Blago, N. (1990). A model to simulate the population dynamics of the codling moth (Cydia Pomonella L. (Lepidoptera, Torticidae)): development and male moth flight. Acta Hortic. 276: 43-52

Lough, J. M., Wigley, T M. L., Palutikof, J. P. (1984). Climate and climate impact scenarios for Europe in a warmer world. J. Clim. appl. Meteorol. 22: 1673-1684

Manabe, S., Spelman, M. J., Stouffer, R. J (1992). Transient responses of a coupled ocean-atmosphere model to gradual changes of atmospheric $\mathrm{CO}_{2}$. Part II: Seasonal response. J. Clim. 5: 105-126

Manabe, S., Stouffer, R. J., Spelman, M. J., Bryan, K. (1991). Transient responses of a coupled ocean-atmosphere model to gradual changes of atmospheric $\mathrm{CO}_{2}$. Part I: Annual mean response. J. Clim. 4: 785-818

Mearns, L. O., Katz, R. W., Schneider, S. S. (1984). Extreme high-temperature events: changes in their probabilities with changes in mean temperature. J. Clim. appl. Meteorol. 23: $1601-1613$

Parry, M. L., Carter, T R., Konjin, N. T (eds.) (1988). The impact of climatic variations on agriculture, Vol. 1: Assessments in cool, temperate and cold regions. Kluwer Academic, Dordrecht

Pittock, A. B., Salinger, M. J. (1982). Towards regional scenarios for a $\mathrm{CO}_{2}$-warmed earth. Clim. Change 4: 23-40

Preisendorfer, R. W., Zwiers, F. W., Barnett, T. P. (1981). Foundations of principal component selection rules. SIO Ref. Series 81-4, Scripps Institution of Oceanography La Jolla, CA

Roth, O., Derron, J., Fischlin, A., Nemecek, T, Ulich, M. (in press). Implementation and parameter adaptation of a potato crop simulation model combined with a soil water subsystem. In: van den Broek, B., Marshall, B. (eds.) Proc. 1st Int. Workshop on Potato Modelling, May 29-31, 1990, International Agricultural Centre Wageningen, The Netherlands. Pudoc, Wageningen

Schröder, W (1976). Zur Populationsökologie und zum Management des Rothirsches (Cervus elaphus L.) dargestellt an einem Simulationsmodell und der Reproduktionsleistung des Rothirschbestandes im Harz. Habilitationsschrift, Ludwig-Maximilians-Universität, München

Schüepp, M. Schirmer, H. (1977). Climates of central Europe. In: Wallén, C. C. (ed.) Climates of central and southern Europe. World survey of climatology. Elsevier, Amsterdam p. $3-74$

Schweingruber, F H. (1988). Climatic information for the past hundred years in width and density of conifer growth rings. In: Wanner, H., Siegenthaler, U. (eds.) Long and short term variability of climate. Lecture notes in earth sciences, 16. Springer, Berlin, p. 35-56

Shugart, H. H. (1984). A theory of forest dynamics. The ecological implications of forest succession models. Springer, New York

SMA (1901-1980). Annalen der Schweizerischen Meteorologischen Anstalt. Schweizerische Meteorologische Anstalt. Zürich 
Spitters, C. J. T., van Keulen, H., van Kraalingen, D. W. G. (1989). A simple and universal crop growth simulator: SUCROS87. In: Rabbinge, R., Ward, S. A., Van Laar, H. H. (eds.) Simulation and systems management in crop protection. Pudoc, Wageningen, p. 147-181

Stockton, C. W., Boggess, W. R., Meko, D. M. (1985). Climate and tree rings. In: Hecht, A. D. (ed.) Paleoclimate analysis and modeling. John Wiley, New York, p. 71-161

Supit, I. (1986). Manual for generation of daily weather data. Simulation Reports CABO-TT No. 7, Centre for Agrobiological Research, Wageningen

Swartzman, G. L., Kaluzny, S. P. (1987). Ecological simulation primer. Macmillan, New York

Uttinger, H. (1970). Niederschlag. Klimatologie der Schweiz, Vol. E, Parts 5 to 8 . Schweizerische Meteorologische Zentralanstalt, Zürich

Vinnikov, K. Y., Groisman, P. Y., Lugina, K. M., Golubev, A. A. (1987). The mean surface air temperature variations in the Northern Hemisphere over 1841-1985. Meteor. Hydrol. 1: 45-55 (in Russian)

von Storch, H., Zorita, E., Cubasch, U. (1993). Downscaling of global climate change estimates to regional scales: an

Editor: G. Esser, Gießen, Germany applicaton to Iberian rainfall in wintertime. J. Clim. 6: $1161-1171$

Werner, P., von Storch, H. (1993). Interannual variability of Central European mean temperature in January/February and its relation to large-scale circulation. Clim. Res. 3: 195-207

Wigley, T M. L., Jones, P. D., Briffa, K. R., Smith, G. (1990). Obtaining sub-grid scale information from coarseresolution general circulation model output. J. geophys. Res. 95: 1943-1953

Wigley, T M. L., Jones, P. D., Kelly, P. M. (1980). Scenario for a warm, high $\mathrm{CO}_{2}$ world. Nature 283: 17-21

Wigley, T. M. L., Jones, P. D., Kelly, P. M. (1986). Empirical climate studies. In: Bolin, B. et al. (eds.) The greenhouse effect, climatic change and ecosystems. John Wiley, New York, p. 271-322

Wilks, D. S. (1989). Statistical specification of local surface weather elements from large-scale information. Theor appl. Climatol. 40: 119-134

Wilks, D. S. (1992). Adapting stochastic weather generation algorithms for climate change studies. Clim. Change 22: $67-84$

Manuscript first received: July 17, 1993

Revised version accepted: June 23, 1994 